\title{
Molecular Marker Study of Particulate Organic Matter in Southern Ontario Air
}

\author{
Satoshi Irei, ${ }^{1}$ Jacek Stupak, ${ }^{1}$ Xueping Gong, ${ }^{1}$ Tak-Wai Chan, ${ }^{2}$ Michelle Cox, \\ Robert McLaren, ${ }^{1}$ and Jochen Rudolph ${ }^{1}$ \\ ${ }^{1}$ Centre for Atmospheric Chemistry and Department of Chemistry, York University, 4700 Keele St., Toronto, ON, Canada M3J 1P3 \\ ${ }^{2}$ Climate Chemistry Measurements and Research, Climate Research Division, Environment and Climate Change Canada, \\ 4905 Dufferin Street, Toronto, ON, Canada M3H 5 T4
}

Correspondence should be addressed to Satoshi Irei; satoshi.irei@gmail.com

Received 28 April 2017; Accepted 28 June 2017; Published 17 September 2017

Academic Editor: Adam Voelkel

Copyright ( 2017 Satoshi Irei et al. This is an open access article distributed under the Creative Commons Attribution License, which permits unrestricted use, distribution, and reproduction in any medium, provided the original work is properly cited.

To study the origins of airborne particulate organic matter in southern Ontario, molecular marker concentrations were studied at Hamilton, Simcoe, and York Gateway Tunnel, representing industrial, rural, and heavy traffic sites, respectively. Airborne particulate matter smaller than $10 \mu \mathrm{m}$ in aerodynamic diameter was collected on quartz filters, and the collected samples were analyzed for total carbons, 5-6 ring PAHs, hopanes, $n$-alkanes $\left(C_{20}\right.$ to $\left.C_{34}\right)$, and oxygenated aromatic compounds. Results showed that PAH concentrations at all three sites were highly correlated, indicating vehicular emissions as the major source. Meanwhile, in the scatter plots of $\alpha, \beta$-hopane and trisnorhopane, concentrations displayed different trends for Hamilton and Simcoe. The slopes of the linear regressions for Hamilton and the tunnel were statistically the same, while the slope for Simcoe was significantly different from those. Comparison with literature values revealed that the trend observed at Simcoe was explained by the influence from coal combustion. We also found that the majority of oxygenated aromatic compounds at both sites were in the similar level, possibly implying secondary products contained in the southern Ontario air. Regardless of some discrepancies, absolute principal component analysis applied to the datasets could reproduce those findings.

\section{Introduction}

Studying chemical composition of airborne particulate matter (PM) is very important to understand the terrestrial radiative forcing [1] and the adverse health effect [2]. Organic fraction in airborne particulate matter (particulate organic matter $(\mathrm{POM}))$ is potentially associated with these issues. Numerous studies have demonstrated that there is no doubt that the POM is the major constituent of airborne particulate matter (e.g., [3]). To date, a number of molecular marker studies have been done for source identification and apportionment of POM [4-8].

The objective here is to better understand the origins of airborne POM during a case study in southern Ontario, Canada. A field campaign was carried out in the summer of 2000 at two locations in southern Ontario, Hamilton, and Simcoe. During the study, hourly averaged mixing ratios of $\mathrm{SO}_{2}$ and 24-hour averaged molecular marker and total carbon
(TC) concentrations in PM were measured. To understand the influence of vehicular emissions, which were expected to be one of the major sources of POM, four times of tunnel studies were carried out in 2000 and 2001. Obtained concentrations were compared to investigate their relationships, which give clues for the source identification. Wind sector dependency was also evaluated to identify the directions of emission sources, and absolute principal component analysis (APCA) was applied to get deeper insight into the sources identification and apportionment.

\section{Methodology}

2.1. Field Study. Southern Ontario Aerosol Studies (SONTAS 2000) were carried out from June 23 to July 19, 2000, at a measurement station located in downtown Hamilton $\left(43^{\circ} 15^{\prime}\right.$ $\mathrm{N}, 79^{\circ} 51^{\prime} \mathrm{W}$ ) and another site located near the agricultural field of University of Guelph in the town of Simcoe $\left(42^{\circ} 51^{\prime}\right.$ 
$\mathrm{N}, 80^{\circ} 16^{\prime} \mathrm{W}$ ) (Figure 1). These sites represent an industrial site and a rural site in southern Ontario, respectively. During the study, airborne particulate matter smaller than $10 \mu \mathrm{m}$ in aerodynamic diameter $\left(\mathrm{PM}_{10}\right)$ was collected on $8 \times 10$ inch Pallflex Tissuquartz filters (Pall Corp., NY, USA) using high volume air samplers equipped with $\mathrm{PM}_{10}$ separators (Tisch Environmental Inc., Cleves, OH, USA). The filters were heated to $750^{\circ} \mathrm{C}$ for more than $4 \mathrm{~h}$ prior to the use. The sampling flow rate was set to $1.13 \mathrm{~m}^{3} \mathrm{~min}^{-1}$, compatible with the sampling requirement for $\mathrm{PM}_{10}$ collection. Sampling duration was $24 \mathrm{~h}$ during the campaign, except some periods: $4 \mathrm{~h}$ sampling was made on July 1st and 2nd at Hamilton and Simcoe, and $12 \mathrm{~h}$ sampling was made on July 13 at Simcoe. Samples on July 14 and 15 at Hamilton and July 18 at Simcoe were not collected. In total, 28 and $33 \mathrm{PM}_{10}$ samples and 7 and 10 field blanks were collected at Hamilton and Simcoe, respectively. It should be noted that we refer to the date on which the sampling started as the sample name. It should also be noted that the $4 \mathrm{~h}$ samples collected on July 1st and 2nd were excluded from the analysis because we found that the impact of blank values on the samples with small loading was relatively high. In addition to the SONTAS, four times of tunnel studies were carried out at the York Gateway Tunnel (YGT) in downtown Toronto (June 1st, August 24th, and September 21st, 2000, and February 21st, 2001) to characterize molecular marker concentrations from vehicular emissions. Due to high molecular marker concentrations, only $4 \mathrm{~h}$ sampling was made. In total, five $\mathrm{PM}_{10}$ samples and one field blank were collected during the tunnel study. Each filter sample was cut into eight identical sizes, and then one or two segments of each sample were then used for the molecular marker and TC analysis.

2.2. Analysis. Here we analyzed the filter samples for the following nonpolar substances to trace primary POM: polycyclic aromatic hydrocarbons (PAHs) of benzo[a]pyrene $(\mathrm{BaP})$, dibenz $[\mathrm{a}, \mathrm{h}]$ anthracene $(\mathrm{Db})$, indeno[1,2,3-cd]pyrene (Ind), benzo[ghi]perylene (BgP), and coronene (Cor) (purities > 99\%, Sigma-Aldrich Canada, Oakville, ON, Canada); hopane series of trisnorhopane (TrisHp), norneohopane (NorHp), $\alpha, \beta$-hopane (abHp), and $\beta, \alpha$-hopane (baHp) (purities > 99\%, Chiron AS, Norway); and $n$-alkanes with the carbon numbers from $\mathrm{C}_{20}$ to $\mathrm{C}_{34}$ (purities $>99 \%$, SigmaAldrich Canada). The details of the nonpolar molecular marker analysis are described elsewhere [21]. Briefly, one or two pieces of each filter sample, which 40 and $200 \mathrm{ng}$ of internal standards (benzo[a]pyrene- $\mathrm{d}_{2}$ and tetracosane$d_{50}$, Sigma-Aldrich Canada) were spiked onto, were extracted with $100 \mathrm{~mL}$ of PRA grade dichloromethane (Sigma-Aldrich Canada) using Soxhlet apparatus (Sigma-Aldrich Canada) for 16 hours. The extract was transferred to a $200 \mathrm{~mL}$ round bottom flask, and its volume was reduced to a few $\mathrm{mL}$ using a rotary evaporator (Buchi, New Castle, DE, USA). The concentrated extract and rinse from the flask were combined and filtrated using a $25 \mathrm{~mm}$ o.d. PTFE syringe filter with a pore size of $0.45 \mu \mathrm{m}$ (Chromatographic Specialties, Inc., Brockville, ON, Canada). The volume of extract was further reduced to near dryness in a $5 \mathrm{~mL}$ Reacti-Vial (Pierce, IL, USA) under a gentle stream of pure nitrogen (Praxair
Canada, Mississauga, ON, Canada) and then dissolved in $0.2 \mathrm{~mL}$ of hexane: benzene $(2: 1)$ mixture. Finally, $100 \mathrm{ng}$ of triacontane- $\mathrm{d}_{62}$ (Sigma-Aldrich Canada), the third internal standard, was spiked to the concentrated extract. $5 \mu \mathrm{l}$ of the extract was directly analyzed by a GC-MS (HP 5890 and 5972, Agilent Technologies, USA) using two-minute splitless injection mode. Scanning and selected ion monitoring (SIM) were used to identify and quantify the molecular markers. The identification of the molecular markers was made by comparison with the retention time and the reference mass spectrum obtained by the analysis of chemical standards and from the NIST 98 mass spectrum library. For the purpose of quality control of GC-MS measurements, a reference standard mixture containing $100 \mathrm{ng} \mathrm{mL}^{-1}$ of each substance referred to above was measured after an injection of a sample extract.

We also analyzed the following 11 oxygenated aromatic compounds of polar substances: 4-nitrophenol $\left(4-\mathrm{NO}_{2}\right.$ Phen), 2-hydroxybenzoic acid (2-OH-BA), 3-hydroxybenzoic acid (3-OH-BA), 4-hydroxybenzoic acid (4-OH-BA), ortho-phthalic acid (o-PhA), meta-phthalic acid $(m-\mathrm{PhA})$, para-phthalic acid ( $p$-PhA), 4-methylphthalic acid (4-MePhA), 1,2,3-benzenetricarboxylic acid (1,2,3-BA), 1,2,4-benzenetricarboxylic acid (1,2,4-BA), and 1,2,4,5-benzenetetracarboxylic acid (1,2,4,5-BA) (Sigma-Aldrich Canada). Analysis of these polar substances is described elsewhere [22]. Briefly, one or two pieces of each filter sample were spiked with $m$-toluic acid as an internal standard, and the filter sample was then extracted with a mixture of $10 \mathrm{~mL}$ of diethyl ether (Sigma-Aldrich Canada) and $1 \mathrm{~mL}$ of $0.1 \mathrm{M}$ hydrochloric acid solution by stirring for 1.5 hours. In the strongly acidified water, the polar substances are partitioned to diethyl ether phase. The diethyl ether extract was filtered using the syringe filter referred to above. This extraction procedure was repeated two more times with $2 \mathrm{~mL}$ of the solvent mixture. The extracts were combined together, and the combined volume was reduced under a gentle flow of nitrogen until being dried. The dried extract was then dissolved in $100 \mu \mathrm{l}$ of $2 \mathrm{mM}$ boric acid, the $\mathrm{pH}$ of which was preadjusted to 9.9 with sodium hydroxide. The extract prepared in this manner was analyzed by a capillary electrophoresis coupled with an UV/visible diode array detector (3DCE, Agilent Technologies).

The details of TC measurement are described elsewhere [23]. Briefly, a disc with $1.5 \mathrm{~cm}$ diameter was punched out from a segment of each filter sample and analyzed by a custom-made thermal desorption TC analyzer. The TC analyzer consists of a desorbing oven operated at $800^{\circ} \mathrm{C}$ and followed by an oxidation furnace and a flame ionization detector. The instrument quantifies $\mathrm{CO}_{2}$ evolving from the combustion of organic carbon and from thermal decomposition of inorganic carbonate. It should be noted that all concentrations of molecular markers and TC hereafter are blank-corrected.

Sulfur dioxide $\left(\mathrm{SO}_{2}\right)$ was also measured at Hamilton and Simcoe. The ambient air was sampled from the rooftop and the measurements were made using $\mathrm{SO}_{2}$ analyzers (Model 43C, Thermo Environmental). Hourly meteorological elements for Hamilton were obtained from the meteorological 


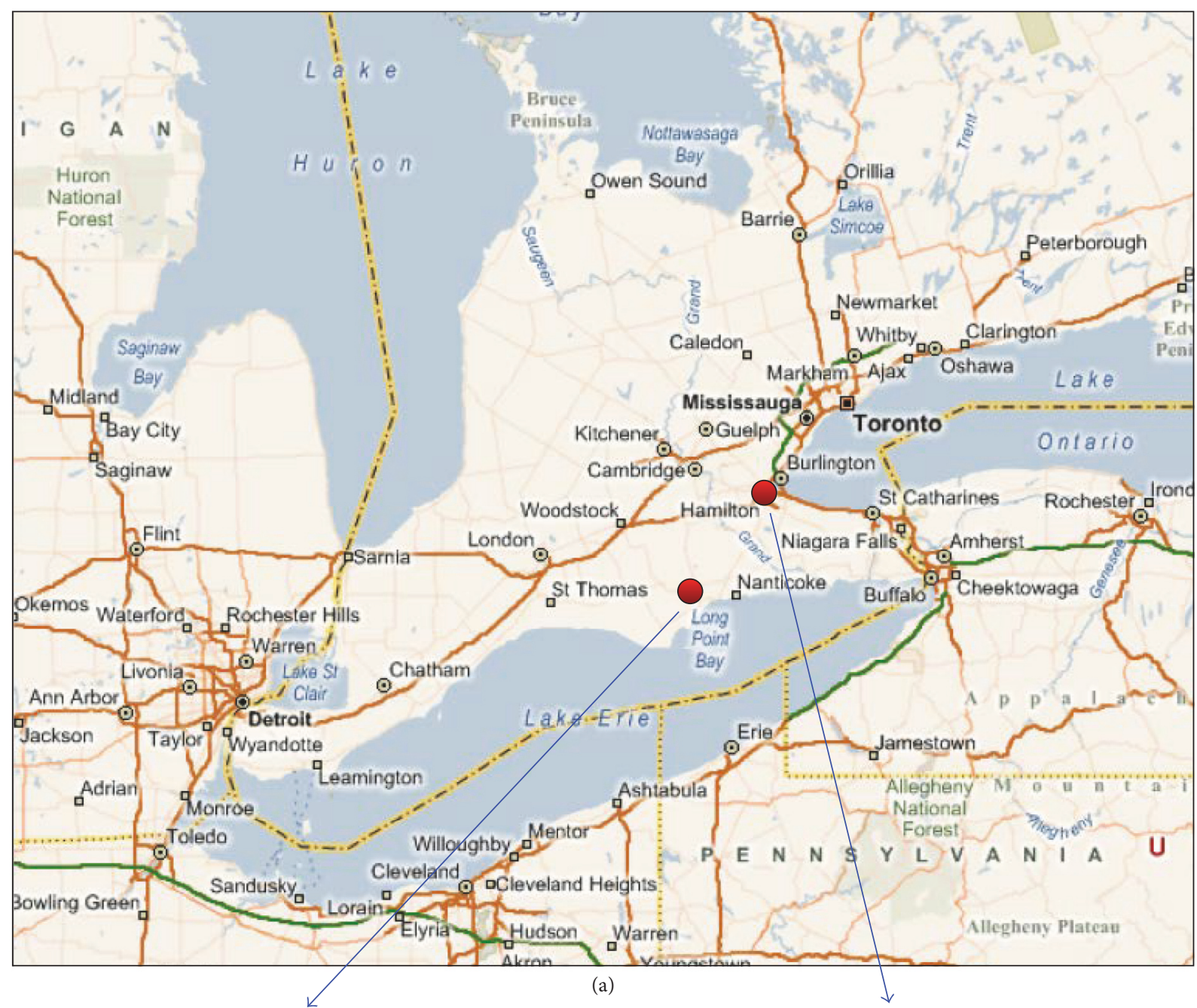

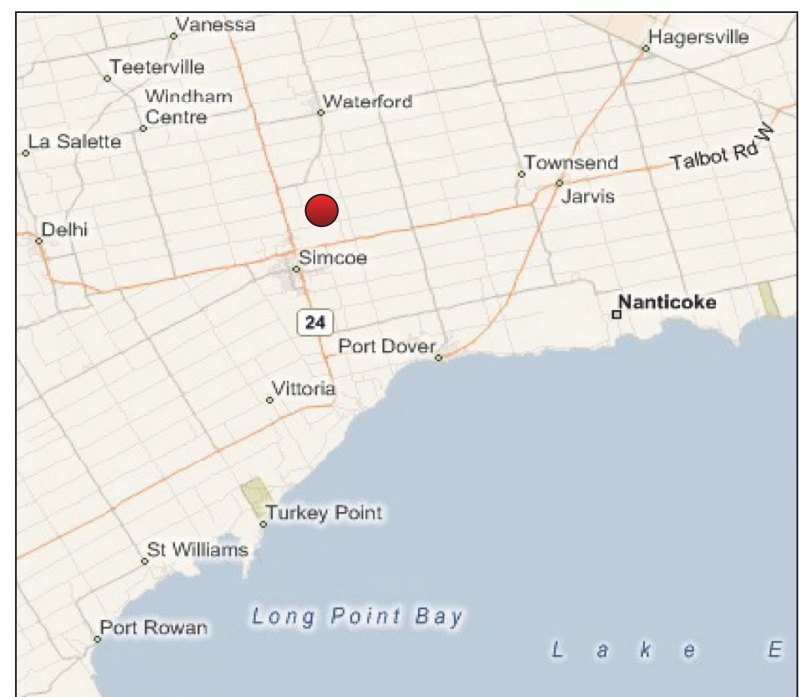

(b)

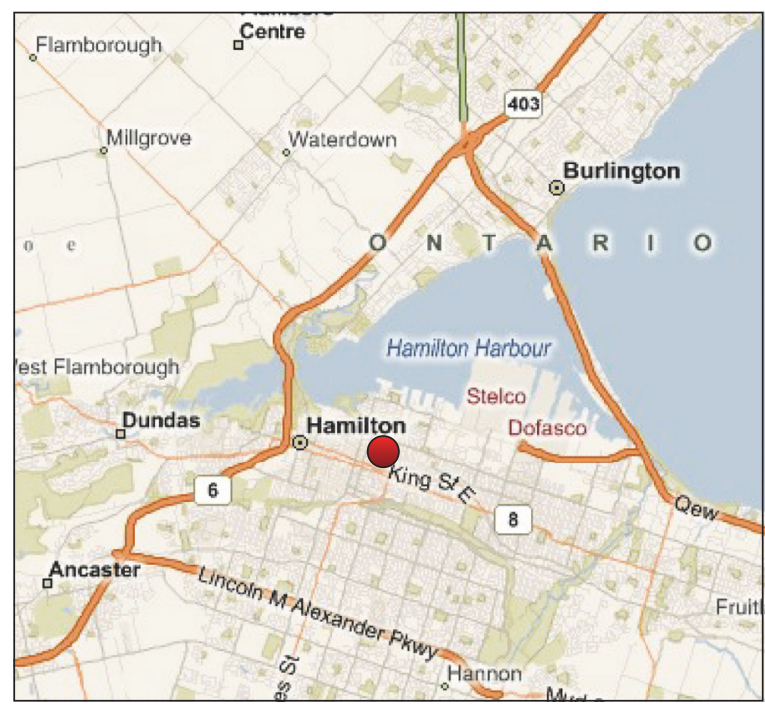

(c)

FIGURE 1: Location of sampling stations for the SONTAS 2000: southern Ontario (a), Simcoe (b), and Hamilton (c). Source: http://mappoint.msn.com. 
archives in Environment Canada. For Simcoe, hourly wind speeds and sectors were provided by Rotek Environmental Inc. (Hamilton, ON, Canada).

2.3. APCA. APCA has been applied to our POM dataset to attempt better understanding of source types. The details of APCA have been described elsewhere [24]. The minimum number of components has been determined by scree plots, and the optimum number of components was then determined by checking scree plots and distribution patterns of molecular markers in each component.

\section{Results and Discussion}

3.1. Observation Records. The following are important records written at the site of Simcoe; grass of the campus yard around the sampling site was mowed on June 26-28 and July 19; smells of burning were recorded at Simcoe between July 8 and July 14 from west of the sampling site: clear influence of a plume from the Nanticoke coal-fired power plant (located approximately $20 \mathrm{~km}$ southeast of the sampling site of Simcoe) was visually observed at Simcoe on July 12. This event may have influenced the molecular marker concentrations of the sample, namely, July 11 (i.e., the sample collected from July 11 through July 12).

3.2. Concentration Level. The mean mixing ratios \pm standard deviations (SD) of $\mathrm{SO}_{2}$ at Hamilton and Simcoe were $3.9 \pm 5.9$ and $2.6 \pm 1.5$, respectively. The minimum and maximum mixing ratios for these sites were $0-30 \mathrm{ppbv}$ and 0-12 ppbv, respectively. Although the difference between the mean concentrations is insignificant, the comparison of variations indicates local emission source(s) of $\mathrm{SO}_{2}$ at Hamilton. Observed mean concentrations and concentration ranges of TC and molecular markers during our field studies are summarized in Table 1. Overall, there were differences between Hamilton and Simcoe in the concentrations of TC, PAHs, hopanes, some $n$-alkanes, and oxygenated aromatic compounds such as 3-OH-BA and 4-Me-PhA. The differences indicate the air quality difference between the industrial urban site and the rural site in southern Ontario. There were also substances that did not show the air quality difference, such as TrisHp, the majority of $n$-alkanes, and oxygenated aromatic substances. This implies that for these substances there were some major other local emission sources at Simcoe or that those substances were contained in the large air mass covering southern Ontario. The mean concentrations of these molecular markers at the YGT were much higher than those at Hamilton (3 to 20 times higher mean concentrations).

Comparison of the mean marker concentrations with those observed in different field studies is shown in Table 2. The mean PAH concentrations observed at Hamilton during SONTAS 2000 were compared with the concentrations observed at the same sampling station in 1990 [9], and we found that the concentration ranges during SONTAS 2000 were more than 10 times lower than those reported in the literature. This is probably explained by the fact that the factory emissions, which were the major POM source in Hamilton, may have been reduced substantially. Comparison with the other studies at other locations reveals that the mean concentrations of molecular markers during SONTAS 2000 were almost of the same level as the concentrations observed in other cities (Philadelphia, Atlanta, and Houston) of the United States [10-12]. It is also interesting to compare the concentrations observed during our tunnel studies with the other tunnel studies in Los Angeles [13]. The variation patterns of molecular markers from our tunnel studies and their tunnel studies agreed (Table 2), suggesting that these molecular markers can be used as the fingerprint for vehicular emission overall.

3.3. Time Series Variation. Time series plot of daily frequency of wet deposition (rain and fog) occurrence at Hamilton and time series plots of TC and molecular marker concentrations at both Hamilton and Simcoe are shown in Figures S1 and S-2 in Supplementary Material available online at https://doi.org/10.1155/2017/3504274, respectively. The daily frequency of wet deposition occurrence is the counts of hourly rain and fog events relative to the sampling hour (i.e., $24 \mathrm{~h}$ or $12 \mathrm{~h}$ ). Comparison of these plots shows that the frequency of wet deposition was not negatively correlated with the concentrations of any species $\left(r^{2}<0.19\right)$. However, the poor correlations do not necessarily rule out the washout of POM by the precipitations because the molecular marker concentrations depend on the combination of many factors, such as wind speed, strength of emission rate, and frequency and strength of wet deposition. The wet depositions were observed at both sites in the similar days, and this can be explained by the fact that the precipitations observed at Hamilton and Simcoe were the regional scale events.

Time series plot of hourly averaged $\mathrm{SO}_{2}$ mixing ratios at Hamilton showed sharp rises and falls, each of which lasted for 1 to 10 hours (Figure S-2a). These observations cannot be explained by diesel emissions only because the mobile sources would not continuously contribute to the input of $\mathrm{SO}_{2}$ into Hamilton's air. The observations are more likely explained by the combination of diesel emissions and factory emissions combusting coal or cokes. Time series plot of hourly averaged $\mathrm{SO}_{2}$ mixing ratios at Simcoe shows much smaller variations due to considerably lower mixing ratios than Hamilton (Figure S-2b). Nevertheless, some small peaks were observed. These peaks suggest that there are local sources of $\mathrm{SO}_{2}$ at Simcoe.

Time series variation of TC concentrations showed marginal variations at both sites and any remarkably high or low concentration episode was not observed (Figures S$3 \mathrm{a}$ and $3 \mathrm{~b}$ ). The variations were not as large as the variations of molecular markers and $\mathrm{SO}_{2}$, indicating that there are other carbonaceous substances in the filter samples.

In the time series plot of PAHs at Hamilton, the highest concentrations of the PAHs were observed on June 23, and this was a local event because such a high concentration was not observed at Simcoe (Figures S-3c and 3d). Marginally high concentrations of PAHs were also observed from July 3-7 and July 10-13, and the concentrations were low between these episodes, during which precipitation was recorded. Those levels of concentrations were more likely usual at Hamilton. At Simcoe, the levels of PAHs were significantly 
TABLE 1: Mean of molecular marker concentration and concentration range observed during the SONTAS 2000.

\begin{tabular}{|c|c|c|c|}
\hline Location & Hamilton $(n=28)$ & Simcoe $(n=34)$ & Toronto Tunnel $(n=5)$ \\
\hline Ext. method & $\begin{array}{l}\text { Soxhlet and } \\
\text { sonication }\end{array}$ & Soxhlet and sonication & Soxhlet and sonication \\
\hline Sample type & $\mathrm{PM}_{10}$ & $\mathrm{PM}_{10}$ & $\mathrm{PM}_{10}$ \\
\hline Filter media ${ }^{a}$ & Quartz filter & Quartz filter & Quartz filter \\
\hline Sampling time & $24 \mathrm{~h}$ & $\begin{array}{c}24 \mathrm{~h} \\
\left(\mathrm{ng} \mathrm{m}^{-3}\right)\end{array}$ & $4 \mathrm{~h}$ \\
\hline \multicolumn{4}{|l|}{ PAHs } \\
\hline Benzo[a]pyrene (BaP) & $0.105(0.009-0.608)$ & $0.023(<\mathrm{DL}-0.133)$ & $0.513(0.165-1.212)$ \\
\hline Dibenz[a,h]anthracene $(\mathrm{Db})$ & $0.030(0.004-0.131)$ & $0.016(0.001-0.073)$ & $0.075(0.005-0.162)$ \\
\hline Indeno[1,2,3-cd]pyrene (Ind) & $0.184(0.019-0.804)$ & $0.070(0.001-0.447)$ & $0.659(0.230-1.501)$ \\
\hline Benzo[ghi]perylene (BghiP) & $0.175(0.023-0.605)$ & $0.049(0.011-0.265)$ & $1.495(1.054-2.380)$ \\
\hline Coronene (Cor) & $0.052(0.014-0.143)$ & $0.019(0.006-0.082)$ & $0.754(0.488-1.181)$ \\
\hline \multicolumn{4}{|l|}{ Hopanoids } \\
\hline $17 \alpha(\mathrm{H})-22,29,30-$ Trisnorhopane (TrisHp) & $0.132(0.022-0.326)$ & $0.181(0.028-0.530)$ & $4.166(2.234-8.811)$ \\
\hline $17 \beta(\mathrm{H}), 21 \alpha(\mathrm{H})-30$-Norhopane (NorHp) & $0.044(0.004-0.111)$ & $0.019(0.007-0.052)$ & $1.000(0.640-1.747)$ \\
\hline $17 \alpha(\mathrm{H}), 21 \beta(\mathrm{H})$-Hopane (abHp) & $0.342(0.043-0.887)$ & $0.154(0.068-0.445)$ & $11.788(7.394-22.476)$ \\
\hline $17 \beta(\mathrm{H}), 21 \alpha(\mathrm{H})$-Hopane (baHp) & $0.072(0.007-0.190)$ & $0.014(0.006-0.042)$ & $1.289(0.838-2.309)$ \\
\hline \multicolumn{4}{|l|}{ n-Alkanes } \\
\hline Eicosane (C20) & $1.150(<\mathrm{DL}-4.370)$ & $1.216(<\mathrm{DL}-6.036)$ & $59.297(45.454-97.709)$ \\
\hline Heneicosane (C21) & $1.835(0.241-6.425)$ & $1.351(0.058-6.855)$ & $40.047(22.276-54.842)$ \\
\hline Docosane (C22) & $1.410(0.222-3.625)$ & $1.288(0.066-6.020)$ & $35.134(14.490-56.449)$ \\
\hline Tricosane (C23) & $2.738(0.384-6.309)$ & $2.414(0.272-10.399)$ & $31.766(11.235-69.772)$ \\
\hline Tetracosane (C24) & $1.363(0.231-4.634)$ & $0.704(0.119-2.249)$ & $18.945(7.760-41.957)$ \\
\hline Heptacosane (C25) & $2.159(0.473-6.264)$ & $1.608(0.274-10.980)$ & $17.462(5.061-40.785)$ \\
\hline Hexacosane (C26) & $1.116(0.007-4.967)$ & $0.642(0.081-12.471)$ & $9.431(4.523-17.813)$ \\
\hline Heptacosane (C27) & $3.092(1.007-9.058)$ & $2.210(0.467-15.265)$ & $16.125(8.581-29.425)$ \\
\hline Octacosane (C28) & $1.469(0.065-6.889)$ & $0.968(<\mathrm{DL}-21.051)$ & $11.115(5.559-15.220)$ \\
\hline Nonacosane (C29) & $3.790(1.149-9.589)$ & $3.175(0.351-10.378)$ & $14.042(8.656-22.051)$ \\
\hline Triacontane (C30) & $1.383(0.130-7.528)$ & $0.504(<\mathrm{DL}-8.762)$ & $10.923(7.053-15.800)$ \\
\hline Hentriacontane (C31) & $4.160(1.913-10.451)$ & $2.700(0.940-11.769)$ & $27.290(13.958-46.388)$ \\
\hline Dotriacontane (C32) & $0.611(<\mathrm{DL}-3.205)$ & $0.254(<\mathrm{DL}-3.798)$ & $10.498(5.550-29.022)$ \\
\hline Tritriacontane (C33) & $0.992(0.345-3.801)$ & $0.518(0.038-3.617)$ & $12.297(5.663-22.460)$ \\
\hline Tetratriacontane (C34) & $0.286(<\mathrm{DL}-1.352)$ & $0.190(<\mathrm{DL}-1.689)$ & $6.774(3.591-9.015)$ \\
\hline \multicolumn{4}{|l|}{ Oxygenated aromatic compounds } \\
\hline 4-Nitrophenol (4-NO2-Phen) & $0.727(0.204-1.667)$ & $0.408(<\mathrm{DL}-1.840)$ & $9.471(2.599-25.090)$ \\
\hline 2-Hydroxybenzoic acid (2-OH-BA) & $0.724(0.204-1.473)$ & $0.545(0.086-1.827)$ & $13.774(4.367-38.145)$ \\
\hline 3-Hydroxybenzoic acid (3-OH-BA) & $0.144(<\mathrm{DL}-0.467)$ & $0.052(<\mathrm{DL}-0.469)$ & $6.298(2.144-18.535)$ \\
\hline 4-Hydroxybenzoic acid (4-OH-BA) & $0.687(0.349-1.096)$ & $0.272(0.022-0.988)$ & $9.963(2.201-32.593)$ \\
\hline 4-Methylphthalic acid (4-Me-PhA) & $2.719(1.287-6.420)$ & $1.245(0.103-6.706)$ & $17.871(5.490-44.862)$ \\
\hline Para-phthalic acid ( $p$-PhA) & $1.666(0.660-3.385)$ & $1.452(0.288-3.716)$ & $11.667(2.980-34.641)$ \\
\hline Meta-phthalic acid ( $m$-PhA) & $0.487(0.209-1.158)$ & $0.358(0.145-0.775)$ & $9.232(1.410-29.403)$ \\
\hline Ortho-phthalic acid (o-PhA) & $10.481(<\mathrm{DL}-23.689)$ & $11.672(4.664-22.977)$ & $53.311(18.578-162.944)$ \\
\hline $\begin{array}{l}\text { 1,2,3-Tricarboxylic benzoic acid } \\
(1,2,3-\mathrm{BA})\end{array}$ & $2.725(0.731-4.837)$ & $3.029(0.814-8.409)$ & $15.760(1.434-52.148)$ \\
\hline $\begin{array}{l}\text { 1,2,4-Tricarboxylic benzoic acid } \\
(1,2,4-\mathrm{BA})\end{array}$ & $3.307(1.194-16.006)$ & $2.460(0.796-5.831)$ & $23.465(2.540-67.539)$ \\
\hline $\begin{array}{l}\text { 1,2,4,5-Tetracarboxylic benzoic acid } \\
(1,2,4,5-\mathrm{BA})\end{array}$ & $0.579(0.220-1.508)$ & $0.391(0.059-0.909)$ & $5.808(0.523-17.536)$ \\
\hline
\end{tabular}

The mean values of atmospheric concentrations observed are given with either the ranges (two values in a bracket) or the standard deviations (a single value in a bracket). 
TABLE 2: Molecular marker concentrations observed in other locations.

\begin{tabular}{|c|c|c|c|}
\hline Location & Hamilton $1990^{\mathrm{a}}(n=33)$ & Philadelphia $1999^{\mathrm{b}} \quad(n=41)$ & Beijing $^{c}$ \\
\hline Ext. method & Soxhlet & Soxhlet & Sonication \\
\hline Sample type & $\mathrm{PM}_{10}$ & $\mathrm{PM}_{10}$ & $\mathrm{PM}_{10}$ \\
\hline Filter media $^{a}$ & $\mathrm{~T}$ & Q & G or $\mathrm{Q}$ \\
\hline Sampling time & $24 \mathrm{~h}$ & $\begin{array}{c}10 \mathrm{~h} \\
\left(\mathrm{ng} \mathrm{m}^{-3}\right)^{\mathrm{b}}\end{array}$ & $24 \mathrm{~h}$ \\
\hline \multicolumn{4}{|l|}{ PAHs } \\
\hline Benzo[a]pyrene (BaP) & $2.0(0.01-12.9)$ & - & 45.6 \\
\hline Indeno $[1,2,3-c d]$ pyrene (Ind) & $3.0(0.03-21.2)$ & - & 30.1 \\
\hline Benzo[ghi]perylene (BghiP) & $4.3(0.07-25.4)$ & - & 33.8 \\
\hline Coronene (Cor) & - & - & - \\
\hline \multicolumn{4}{|l|}{ Hopanoids } \\
\hline $17 \alpha(\mathrm{H})-22,29,30$-Trisnorhopane (TrisHp) & - & $0.107(0.068)$ & 12.1 \\
\hline $17 \beta(\mathrm{H}), 21 \alpha(\mathrm{H})-30$-Norhopane (NorHp) & - & - & 16.6 \\
\hline $17 \alpha(\mathrm{H}), 21 \beta(\mathrm{H})$-Hopane (abHp) & - & $0.317(0.151)$ & 26.4 \\
\hline $17 \beta(\mathrm{H}), 21 \alpha(\mathrm{H})$-Hopane (baHp) & - & - & 13.2 \\
\hline \multicolumn{4}{|l|}{ n-Alkanes } \\
\hline Eicosane (C20) & - & - & 102.1 \\
\hline Heneicosane (C21) & - & - & 146.2 \\
\hline Docosane (C22) & - & - & 170.4 \\
\hline Tricosane (C23) & - & $0.32(0.21)$ & 180.9 \\
\hline Tetracosane (C24) & - & $0.55(0.57)$ & 148.4 \\
\hline Heptacosane (C25) & - & $1.60(1.29)$ & 128.1 \\
\hline Hexacosane (C26) & - & $0.85(1.09)$ & 80.6 \\
\hline Heptacosane (C27) & - & $1.90(1.16)$ & 60.1 \\
\hline Octacosane (C28) & - & $0.670(1.02)$ & 32.4 \\
\hline Nonacosane (C29) & - & $2.94(1.89)$ & 42.8 \\
\hline Triacontane (C30) & - & $0.49(0.74)$ & 20.2 \\
\hline Hentriacontane (C31) & - & $2.32(1.75)$ & 24.9 \\
\hline Dotriacontane (C32) & - & - & 8.8 \\
\hline Tritriacontane (C33) & - & - & 9.3 \\
\hline Tetratriacontane (C34) & - & - & nd \\
\hline \multicolumn{4}{|l|}{ Oxygenated aromatic compounds } \\
\hline 4-Nitrophenol (4-NO2-Phen) & - & - & - \\
\hline 2-Hydroxybenzoic acid (2-OH-BA) & - & - & - \\
\hline 3-Hydroxybenzoic acid (3-OH-BA) & - & - & - \\
\hline 4-Hydroxybenzoic acid (4-OH-BA) & - & - & - \\
\hline 4-Methylphthalic acid (4-Me-PhA) & - & - & - \\
\hline Para-phthalic acid ( $p$-PhA) & - & - & - \\
\hline Meta-phthalic acid ( $m$-PhA) & - & - & - \\
\hline Ortho-phthalic acid (o-PhA) & - & - & - \\
\hline 1,2,3-Tricarboxylic benzoic acid (1,2,3-BA) & - & - & - \\
\hline 1,2,4-Tricarboxylic benzoic acid (1,2,4-BA) & - & - & - \\
\hline $\begin{array}{l}\text { 1,2,4,5-Tetracarboxylic benzoic acid } \\
(1,2,4,5-\mathrm{BA})\end{array}$ & - & - & - \\
\hline
\end{tabular}


TABLE 2: Continued.

\begin{tabular}{|c|c|c|c|}
\hline Location & Houston $1997^{\mathrm{d}}(n=13)$ & Atlanta $1999^{\mathrm{e}}$ & L.A. Tunnel \\
\hline Ext. method & Sonication & Sonication & Sonication \\
\hline Sample type & $\mathrm{PM}_{2.5}$ & $\mathrm{PM}_{2.5}$ & \\
\hline Filter media & $\mathrm{Q}$ & Q & Q \\
\hline Sampling time & $24 \mathrm{~h}$ & $\begin{array}{c}24 \mathrm{~h} \\
\left(\mathrm{ng} \mathrm{m}^{-3}\right)^{\mathrm{a}}\end{array}$ & $\begin{array}{c}4 \mathrm{~h} \\
\left(\mu \mathrm{g} \mathrm{L}^{-1}\right)\end{array}$ \\
\hline \multicolumn{4}{|l|}{$\overline{P A H s}$} \\
\hline Benzo[a]pyrene (BaP) & 0.02 & 0.18 & 18.3 \\
\hline Indeno $[1,2,3-c d]$ pyrene (Ind) & $<\mathrm{DL}$ & 0.26 & 30.6 \\
\hline Benzo[ghi]perylene (BghiP) & 0.01 & 0.55 & 102.2 \\
\hline Coronene (Cor) & - & 0.26 & - \\
\hline \multicolumn{4}{|l|}{ Hopanoids } \\
\hline $17 \alpha(\mathrm{H})-22,29,30-$ Trisnorhopane (TrisHp) & 0.19 & 0.10 & 18.1 \\
\hline $17 \beta(\mathrm{H}), 21 \alpha(\mathrm{H})-30$-Norhopane (NorHp) & - & - & - \\
\hline $17 \alpha(\mathrm{H}), 21 \beta(\mathrm{H})$-Hopane $(\mathrm{abHp})$ & 0.07 & 0.56 & 82.0 \\
\hline $17 \beta(\mathrm{H}), 21 \alpha(\mathrm{H})$-Hopane (baHp) & - & - & - \\
\hline \multicolumn{4}{|l|}{ n-Alkanes } \\
\hline Eicosane (C20) & 0.29 & - & 48.9 \\
\hline Heneicosane (C21) & 0.43 & - & 113.8 \\
\hline Docosane (C22) & 0.61 & - & 123.9 \\
\hline Tricosane (C23) & 0.68 & - & 164.5 \\
\hline Tetracosane (C24) & 2.45 & 3.97 & 229.2 \\
\hline Pentacosane (C25) & 1.58 & 4.00 & 158.4 \\
\hline Hexacosane (C26) & 2.66 & 2.87 & 146.7 \\
\hline Heptacosane (C27) & 1.95 & 2.55 & 104.0 \\
\hline Octacosane (C28) & 1.96 & 1.41 & 77.6 \\
\hline Nonacosane (C29) & 3.04 & 2.36 & 128.3 \\
\hline Triacontane (C30) & 1.45 & 0.87 & 82.2 \\
\hline Hentriacontane (C31) & 3.11 & 1.88 & 93.4 \\
\hline Dotriacontane (C32) & 1.28 & 0.42 & 48.4 \\
\hline Tritriacontane (C33) & 2.37 & 0.50 & 33.7 \\
\hline Tetratriacontane (C34) & - & - & \\
\hline \multicolumn{4}{|l|}{ Oxygenated aromatic compounds } \\
\hline 4-Nitrophenol (4-NO2-Phen) & - & - & - \\
\hline 2-Hydroxybenzoic acid (2-OH-BA) & - & - & - \\
\hline 3-Hydroxybenzoic acid (3-OH-BA) & - & - & - \\
\hline 4-Hydroxybenzoic acid (4-OH-BA) & - & - & - \\
\hline 4-Methylphthalic acid (4-Me-PhA) & - & 1.94 & - \\
\hline Para-phthalic acid ( $p$-PhA) & - & 5.98 & - \\
\hline Meta-phthalic acid $(m-\mathrm{PhA})$ & - & 0.64 & - \\
\hline Ortho-phthalic acid (o-PhA) & - & 5.89 & - \\
\hline 1,2,3-Tricarboxylic benzoic acid (1,2,3-BA) & - & - & - \\
\hline 1,2,4-Tricarboxylic benzoic acid (1,2,4-BA) & - & - & - \\
\hline $\begin{array}{l}\text { 1,2,4,5-Tetracarboxylic benzoic acid } \\
(1,2,4,5-\mathrm{BA})\end{array}$ & - & - & - \\
\hline
\end{tabular}

${ }^{a}$ Cited in Legzdins et al. [9]. ${ }^{b}$ Cited in Shihabut et al. [10]. ${ }^{c}$ Cited in Simoneit et al. (2007). ${ }^{\mathrm{d}}$ Cited in Fraser et al. [11] as the summer data from the HRM-3 site in Houston. ${ }^{\mathrm{e}}$ Cited in Zheng et al. [12] as the data from the Jefferson street in Atlanta. ${ }^{\mathrm{f}}$ Cited in Fraser et al. [13]. 
lower than those at Hamilton; however, there were still local high concentration episodes observed: July 11 and 13 . As mentioned earlier in our records, the episodes were likely the influence of the emissions from the Nanticoke power plant located near the site.

Time series plot of hopanes at Hamilton showed similar variation to those of PAHs (Figures S-3e and 3f). abHp, an indicator for vehicular emissions [13, 25], was the highest level of the hopane series; therefore, it is likely that the major source of PAHs and hopanes was vehicular emissions. The variations of hopanes at Simcoe seem to be different from those of PAHs. Different variations and marginal magnitude of abHp concentrations suggest that their major source may be different from the vehicular emissions.

Time series plots of the sum of all $n$-alkane $\left(\mathrm{C}_{20}\right.$ to $\left.\mathrm{C}_{34}\right)$ concentrations and its carbon preference index (CPI) demonstrate the variable influence of $n$-alkane from anthropogenic and natural emissions (Figures S-3g and 31). CPI is defined as follows $[26,27]$ :

$$
\mathrm{CPI}=\frac{1}{2}\left[\left(\frac{\sum_{i}^{z} \text { odd }}{\sum_{i}^{z-1} \text { even }}\right)+\left(\frac{\sum_{i}^{z} \text { odd }}{\sum_{i+1}^{z+1} \text { even }}\right)\right],
$$

where $\sum$ odd, $\sum$ even, $i$, and $z$ stand for the sum of odd carbon number $n$-alkane concentrations, the sum of even carbon number $n$-alkane concentrations, and the start and end of carbon number range to be summed, respectively. CPI is an indicator to see if $n$-alkanes are originated from petroleumrelated emissions $(\mathrm{CPI}=\sim 1)$ or plant wax origin $(\mathrm{CPI}>3)$ [28-31]. It has been also reported that low CPI was also found in biomass burning [32-34].

The sum of all $n$-alkane concentrations at Hamilton showed remarkably high concentrations on July 5 and 10 with the CPIs $<2$ (Figure S-3g). This is evidence that there was strong influence from the anthropogenic emissions on those samples. If these samples were influenced by biomass burning (such as agricultural waste burning), we expect that the influence would be found in baHp, which is relatively a fresh hopane and can be an indicator of biomass burning [32]. However, such impact was not observed in baHp concentrations. The observations are, therefore, clearly explained by the input from the anthropogenic emissions. The samples collected on June 24, 25, 26, and 30 and July 8 at Hamilton showed CPIs $>3$, an indication of the majority of plant wax $n$ alkanes. However, the magnitudes of the concentrations were smaller than those observed in the other days, suggesting minor contribution of plant wax $n$-alkanes.

The variation of $n$-alkane concentrations at Simcoe was different from that at Hamilton (Figure S-3h). A high concentration episode can be found on July 13 with CPI $<2$. The observation is consistent with the indications found in the PAH and hopane molecular markers that there was a remarkably high influence from the anthropogenic emissions. Besides this apparent episode, many of the samples at Simcoe showed low concentrations with high CPIs. Particularly, the observations in the period of June 26-28 were consistent with our records that the yard maintenance was made during this period. This activity likely released plant wax $n$-alkanes into the air and influenced our samples.

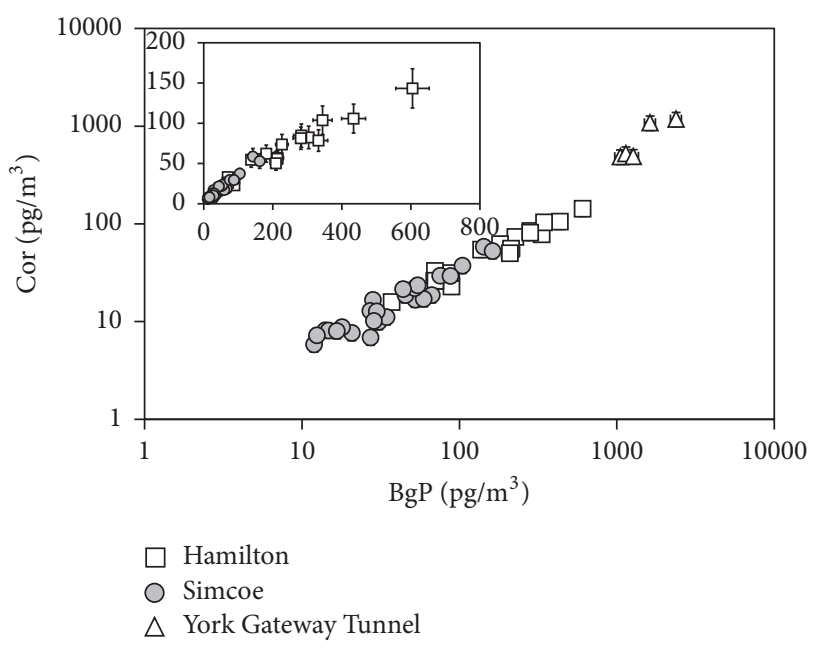

FIGURE 2: Scatter plot of coronene (Cor) concentration versus benzo[ghi]perylene (BgP) concentration. Plots shown are in log-log scale and the inset shown is in expanded linear scale. The slopes of the linear regressions for Hamilton, Simcoe, and YGT are $0.27 \pm 0.01$ $\left(r^{2}=0.914\right), 0.37 \pm 0.01\left(r^{2}=0.933\right)$, and $0.51 \pm 0.04\left(r^{2}=0.802\right)$, respectively. Error bars shown are standard errors estimated from the replicate measurements.

In the time series plots of oxygenated aromatic compounds (Figures $S-3 i, 3 j, 3 k$, and 31 ), their variations were different from those of other substances and extremely high concentrations of 1,2,4-BA and 4-Me-PhA were found in one sample only at Hamilton, July 3 , and another at Simcoe, July 13. Although the explanation for July 13 at Simcoe would be the influence from the anthropogenic emissions found in other substances, we could not find any explanation for the high concentration of 1,2,4-BA at Hamilton.

\section{Molecular Markers}

4.1. PAHs. Overall, BaP, Ind, BgP, and Cor concentrations at all three sites seemed to be highly correlated with each other ( $r^{2}$ ranging from 0.77 to 0.96 ), possibly implying contribution from a single source (e.g., Figure 2). However, the detailed analysis ( $F$-test of one-sided analysis of variance) on slopes of the linear regressions for each site and concentration ratios of two species for each sample revealed that some PAHs showed statistically the same trend (or concentration ratios) at all three sites, but some did not. For example, concentration plots of $\mathrm{BaP}$ versus Ind [21] exhibited a high correlation, and the calculated $F$-value was 0.664 . For the total number of 46 data points obtained from the three locations, the $\alpha$ threshold of $5 \%$ confidence interval for the null hypothesis is 3.2 , which is apparently higher than the calculated $F$-value, justifying that the data from the three locations can be handled together. Thus, the slope \pm standard error of the mean (SE) of the linear regression for $\mathrm{BaP}$ and Ind concentration plots including all the data from the three sites, $0.73 \pm 0.02$, represents the overall $\mathrm{BaP} /$ Ind ratio in the southern Ontario air. The single trend suggests that there was only one dominant and similar source for Ind and $\mathrm{BaP}$ at Hamilton and Simcoe, which is possibly the vehicular emissions, or that weights of contributions from 


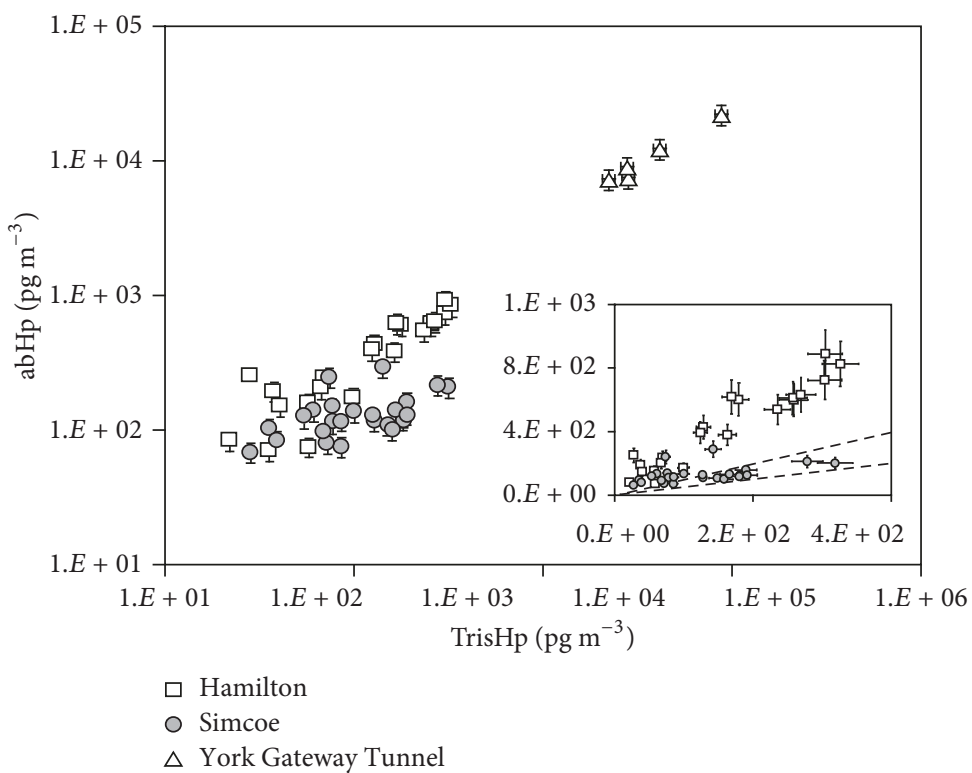

FIGURE 3: Scatter plot of $\alpha, \beta$-hopane (abHp) concentration versus trisnorhopane (TrisHp) concentration in $\mathrm{PM}_{10}$ collected at three different locations. The figure is in logarithm scale, and the inset is in expanded linear scale. The linear regression slopes for the Hamilton, Simcoe, and York Gateway Tunnel samples are $2.6 \pm 0.1\left(r^{2}=0.884\right), 0.89 \pm 0.09\left(r^{2}=-0.579\right)$, and $2.7 \pm 0.1\left(r^{2}=0.953\right)$, respectively. Dotted lines shown in the inset are $y=x$ and $y=0.5 x$, corresponding to the highest and the lowest ratios of $\alpha, \beta$-hopane emission rate to trisnorhopane emission rate for coal combustions studied [19]. Error bars shown are standard errors estimated from the replicate measurements.

the emission sources were, by coincidence, almost the same every day during the study period. Additionally, such a high correlation also implies that these PAHs were fresh because reactive PAHs including Ind and $\mathrm{BaP}$ deplete at different rates in the atmosphere [35-39], resulting in more scattered plot of these concentrations.

In contrast, the same analysis on Cor versus $\mathrm{BgP}$ for the three sites' data (Figure 2) resulted in F-value of 12.4, indicating that the trends of three sites are significantly different. Even the exclusion of YGT data, which show significantly different ratios in Figure 2, resulted in $F$-value of 7.6. The $\alpha$ threshold of $5 \%$ confidence interval for the null hypothesis of $1 \times 43$ degrees of freedom is 4.1 . Thus, we concluded that the slopes of linear regressions for Cor and $\mathrm{BgP}$ concentrations at Hamilton $(0.270 \pm 0.008)$, Simcoe $(0.37 \pm 0.01)$, and YGT $(0.51 \pm 0.04)$ should be treated separately, meaning that the major emission sources for Cor and $\mathrm{BgP}$ are different at these sites.

To identify their sources, the $\mathrm{BaP} /$ Ind $(0.73 \pm 0.02$ for all sites $)$ and Cor/BgP $(0.270 \pm 0.008,0.37 \pm 0.01$, and $0.51 \pm$ 0.04 for Hamilton, Simcoe, and YGT, resp.) were compared with those ratios from the selected literatures reporting the four PAH concentrations from the source studies (Table 3). In this comparison, each concentration was normalized by the sum of the four PAH concentrations. The comparison showed that our $\mathrm{BaP} /$ Ind ratio statistically agrees with the ratio for diesel car emission [16]; thus, we conclude that diesel car emission was the major contributor of $\mathrm{BaP}$ and Ind in the southern Ontario air. The Cor/BgP ratio at YGT was similar to the ratios for the tunnel studies at Baltimore [14] and statistically agreed with gasoline car emission [16], wood burning [16], and emissions from an incinerator [15]. Because we expect that car emissions were predominant at YGT, the gasoline car emissions were likely the major contributor of Cor and BgP at YGT. The Cor/BgP ratios at Hamilton and Simcoe were similar to those of bituminous coal combustion [19] and diesel car emissions [16], respectively. An industry was located near the Hamilton site and there were tractor emissions in the agricultural field near the Simcoe site; therefore, these identifications are plausible. However, it should be noted that there was a coal-fired power plant (Nanticoke power plant) a few kilometers away from the Simcoe site. An impact from this power plant was observed in hopanes (discussed in the following section); thus, we could not rule out the possibility of its significant contribution in Cor and BgP emissions at Simcoe.

4.2. Hopanes. Plots of atmospheric concentrations of abHp and TrisHp (Figure 3) showed that the data points for Hamilton and YGT showed high correlations ( $r^{2}$ of 0.880 and 0.953 , resp.). Their slopes agreed within the uncertainties (2.6 \pm 0.1 for Hamilton and $2.7 \pm 0.1$ for YGT). It is believed that the origin of hopanes from car emissions is microdroplets of engine oil [4]; therefore, we conclude that car emissions were the major sources of abHp and TrisHp at Hamilton. It has been reported that abHp ratio to TrisHp in the emission from gasoline vehicles was in the range from 1.4 to 7.1, while diesel emissions showed the ratio of 3.5 [40]. This suggests that hopanes cannot distinguish between gasoline and diesel car emissions. The concentrations of abHp and TrisHp at Simcoe were not highly correlated but exhibited clear distinguishable trend as the concentrations were high. The slope of linear regression was $0.89 \pm 0.09$, significantly lower than the ratio of abHp to TrisHp from vehicular emissions discussed above. 


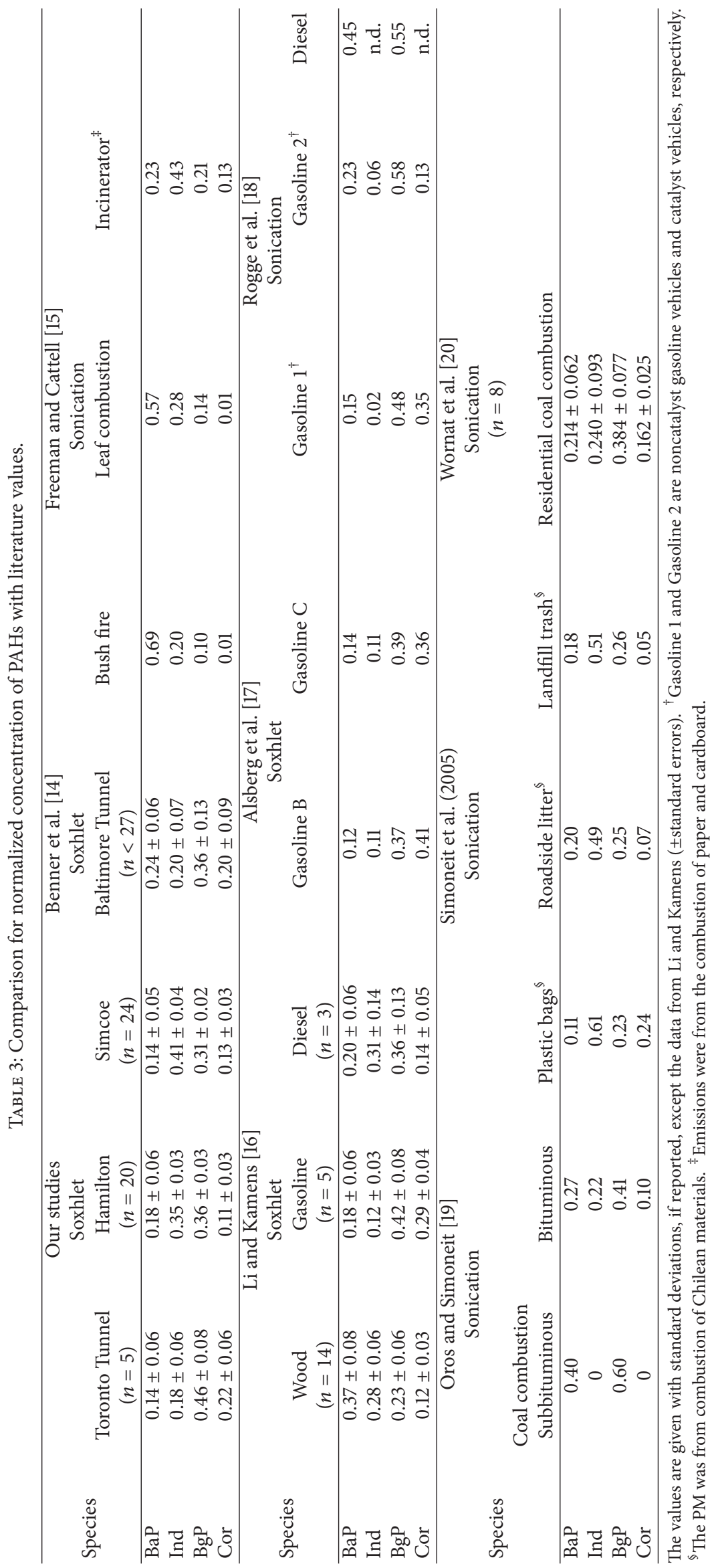




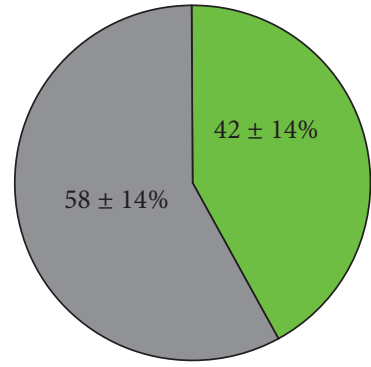

Natural $n$-alkane Anthropogenic $n$-alkane

(a)

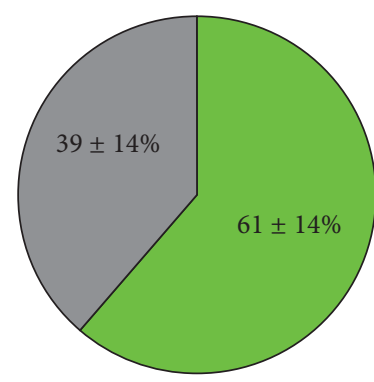

Natural $n$-alkane

Anthropogenic $n$-alkane

(b)

FIGURE 4: Mean percentage \pm standard deviation of plant wax originated and petroleum originated particulate $n$-alkanes at Hamilton and Simcoe during SONTAS 2000.

Oros and Simoneit [19] report that the ratios of abHp to TrisHp for lignite coal, brown coal, subbituminous coal, and bituminous coal were $0.5,1.0,0.8$, and 0.7 , respectively. When the impact of the plume from the Nanticoke provincial power plants was visually observed at Simcoe on July 11, the $\mathrm{abHp} /$ TrisHp ratio in the sample was 0.81 . This agrees with the literature ratio of subbituminous and bituminous coals. Indeed, a report of the provincial government of Ontario states that the Nanticoke power plants used bituminous coals [41]. Although there were some periods where the $\mathrm{abHp} /$ TrisHp ratios from vehicular emissions were observed, the levels of hopane concentrations were small. Thus, we concluded that, at Simcoe, the Nanticoke power plants were likely responsible for the high concentration episodes of hopane series, and there was minor contribution from vehicular emissions.

4.3. $n$-Alkanes. When the series of $n$-alkanes satisfies CPI $=1$, which is the indication of the origin from petroleum-related emissions, the concentration of plant wax $n$-alkane with $n$ carbons $\left(\left[\mathrm{C}_{n}\right]_{\text {plantwax }}\right)$ can then be estimated by the following equation $[42,43]$ :

$$
\left[\mathrm{C}_{n}\right]_{\text {plantwax }}=\left[\mathrm{C}_{n}\right]_{\mathrm{obs}}-\frac{\left\{\left[\mathrm{C}_{n-1}\right]_{\mathrm{obs}}+\left[\mathrm{C}_{n+1}\right]_{\mathrm{obs}}\right\}}{2},
$$

where $n$ is the carbon number of $n$-alkane and $\left[\mathrm{C}_{n}\right]_{\text {obs }}$ is the concentration of $n$-alkane with the $n$th carbon. The equation assumes that the $n$-alkanes were originated only from petroleum-related emissions and plant wax and assumes that all even number $n$-alkanes were originated from petroleum emission. Results showed that the contributions of plant wax $n$-alkanes at Hamilton and Simcoe (average \pm SD) were $42 \pm$ $14 \%$ and $61 \pm 14 \%$, respectively (Figure 4 ). With respect to the concentrations, on average, the sum of particulate $n$ alkane concentrations $( \pm S D)$ at Hamilton and Simcoe was $11300 \pm 3900 \mathrm{pg} \mathrm{m}^{-3}$ and $8700 \pm 2000 \mathrm{pg} \mathrm{m}^{-3}$, respectively. The concentration at Simcoe was slightly lower than the concentration at Hamilton, and this can be explained as more contribution from man-made emissions at Hamilton. Nevertheless, the magnitudes of $n$-alkane concentrations at

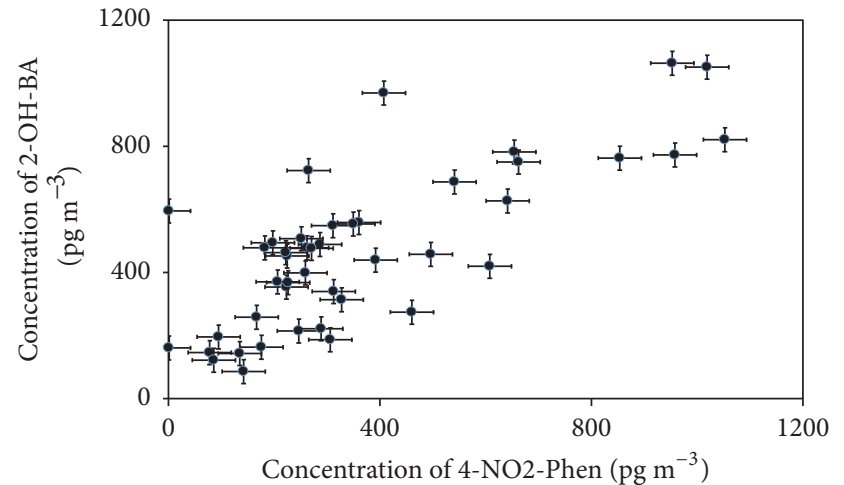

FIGURE 5: Scatter plot of 4-nitrophenol (4-NO2-Phen) concentration versus 2-hydroxybenzoic acid (2-OH-BA) concentration. Error bars shown are the $3 \%$ reproducibility of $\mathrm{CE}$ measurements.

both sites are similar; therefore, the observed levels are more likely the background concentration of airborne particulate plant wax $n$-alkane $\left(\mathrm{C}_{20}-\mathrm{C}_{34}\right)$ in the southern Ontario air.

4.4. Oxygenated Aromatic Compounds. Oxygenated aromatic compounds in airborne POM can be primary $[44,45]$ and secondary products $[5,46,47]$. The high concentrations of these compounds observed at YGT suggest the possibility of their primary origins from vehicular emissions. Scatter plots between the oxygenated aromatic compounds at Hamilton and Simcoe all together gave more detailed ideas on their emission sources.

First, 4- $\mathrm{NO}_{2}$-Phen showed a proportional increase with 2-OH-BA (the highest correlation with $r^{2}=0.855$ ), indicating that $4-\mathrm{NO}_{2}$-Phen and 2-OH-BA were from similar source(s) at Hamilton and Simcoe (Figure 5). Second, excluding the July 13 data due to the apparent influence from the coal-fired power plant at Simcoe, the concentration ratios of Hamilton to Simcoe were significantly larger in $3-\mathrm{OH}-\mathrm{BA}(12 \pm 6$, average $\pm \mathrm{SE})$, 4-OH-BA (13 \pm 3$)$, and $4-\mathrm{Me}-\mathrm{PhA}(13 \pm 3)$ than those in the other oxygenated aromatic compounds $(1.0 \pm$ 


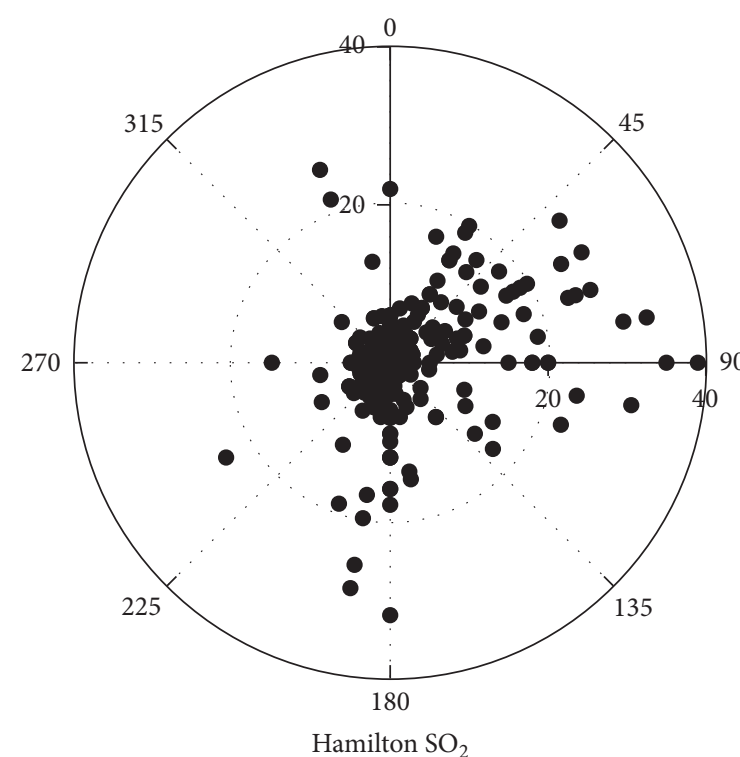

(a)

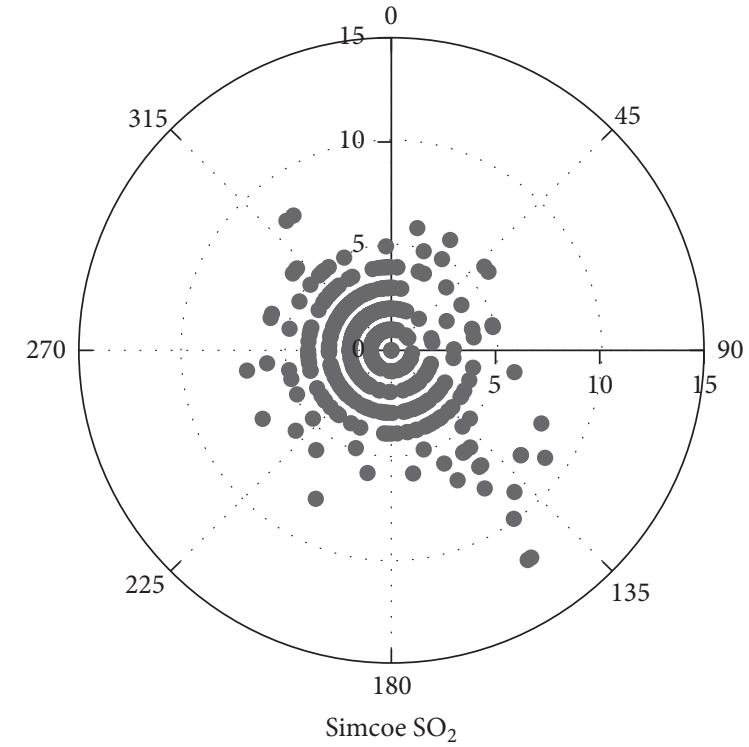

(b)

FIgURE 6: Polar plot of hourly averaged $\mathrm{SO}_{2}$ mixing ratios at (a) Hamilton and (b) Simcoe. Radial axis shown is in ppbv.

$0.3 \sim 2.6 \pm 0.9$ ), suggesting local emission sources for 3-OH$\mathrm{BA}, 4-\mathrm{OH}-\mathrm{BA}$, and 4-Me-PhA at Hamilton. Third, on July 13 , the 3-OH-BA, 4-OH-BA, and 4-Me-PhA concentration levels at Simcoe reached high level similar to the level observed at Hamilton, indicating that coal-fired power plant was their emission source at Simcoe. Fourth, overall, the $o$-PhA, $m$ $\mathrm{PhA}$, and $p$-PhA and 1,2,3-BA, 1,2,4-BA, and 1,2,4,5-BA concentrations at Hamilton and Simcoe were almost in the same levels and were highly correlated $\left(r^{2}=0.627\right.$ or higher $)$. This may imply that the southern Ontario air contained those compounds as background, possibly secondary products.

4.5. Wind Sector Dependence. Hourly averaged wind sectors were compared with the hourly averaged $\mathrm{SO}_{2}$ mixing ratios or daily averaged molecular marker concentrations. In this evaluation, we used wind sectors (from $1^{\circ}$ to $360^{\circ}$ with the north at $360^{\circ}$ ) whose wind speeds were equivalent to or larger than $4 \mathrm{~km} \mathrm{~h}^{-1}$. This filtration resulted in the following: in total, $63 \%$ and $42 \%$ of observed hourly wind sectors were used for the Hamilton and Simcoe data, respectively.

There was clear wind sector dependence on $\mathrm{SO}_{2}$ mixing ratios at Hamilton (Figure 6(a)) and Simcoe (Figure 6(b)). High $\mathrm{SO}_{2}$ mixing ratios were observed as wind was from the directions of $30^{\circ}-90^{\circ}$ and $170^{\circ}-190^{\circ}$ at Hamilton. The influence from the direction of $30^{\circ}-90^{\circ}$ was observed over the six days during the campaign. It has been reported for the same field study at the same site that the size distribution measurements of PM also showed high concentrations of PM in Aitken mode as wind was from the direction of $30^{\circ}-90^{\circ}$ [48]. In this literature, it was concluded that this sector dependence was due to the emission from the industry located $\sim 3 \mathrm{~km}$ northeast to east of the site. Another clear wind sector dependency, $170^{\circ}-190^{\circ}$, was observed only for a short time period (9:00 to 15:00 on June 24). This episode lasted only for 7 hours. Possible sources in the southward are diesel fuelled mobile sources from downtown Hamilton. A clear wind sector dependency was observed at Simcoe as wind was from $120^{\circ}-150^{\circ}$, but the magnitude was low (up to $12 \mathrm{ppb}$ ). As demonstrated by other substances, this was influence from the Nanticoke power plants.

For comparison of the hourly averaged wind sectors with the daily averaged molecular marker concentrations, we used conditional probability function (CPF) [49]:

$$
\mathrm{CPF}=f_{\Delta \theta} \times \frac{m_{\Delta \theta}}{n_{\Delta \theta}} .
$$

In this equation, $n_{\Delta \theta}$ is the total frequency of occurrence of the wind sector between $\theta$ and $\theta+\Delta \theta$ during the whole field study period, $m_{\Delta \theta}$ is the frequency of occurrence of the wind sector during the collection of samples exceeding a threshold concentration, and $f_{\Delta \theta}$ is a weighing factor [50]. Instead of analyzing CPF for individual substance, we performed the analysis for the sum of the same chemical species (i.e., the sum of concentrations of PAHs, hopanes, $n$-alkanes, or the groups of oxygenated aromatic compounds referred to in the previous subsection). We also used the upper 50 percentile concentration for the threshold concentration of each chemical homologue species to extract meaningful dependency and $f_{\Delta \theta}$ of one and $f_{\Delta \theta}$ of a square root of $n_{\Delta \theta}$ over a square root of 10 were used if $n_{\Delta \theta}>10$ and $n_{\Delta \theta} \leq 10$ [48], respectively. The resolution of wind sector, $\Delta \theta$, was set to $20^{\circ}$ in our CPF analysis.

The plots of CPF for the PAH, hopane, and $n$-alkane concentrations during SONTAS 2000 at Hamilton (Figures $7(\mathrm{a})-7(\mathrm{f}))$ showed high concentrations as wind was from the direction of $360^{\circ}$ to $90^{\circ}$ (northerly to easterly), indicating the impact from the emissions from the industry and/or from traffic emissions from the highway of Queen Elizabeth Way (the north to northeast of the sampling station). There was another clear influence from the southeasterly wind on 


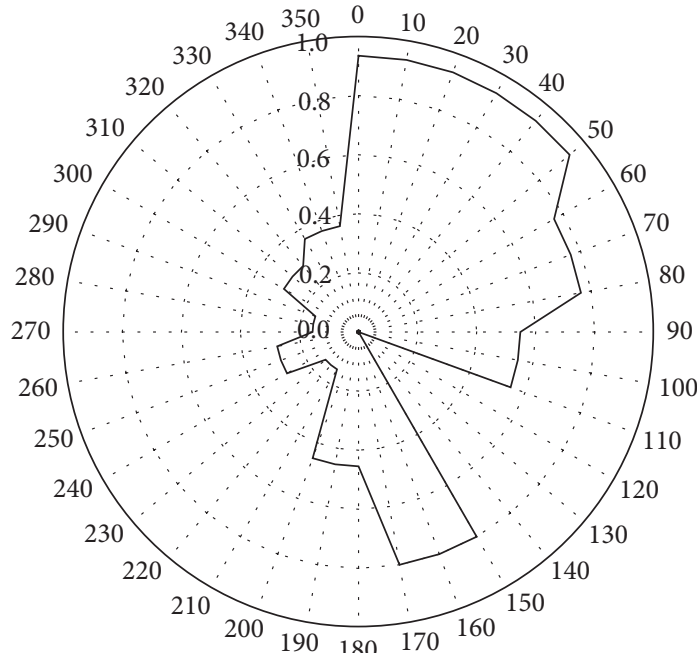

(a)

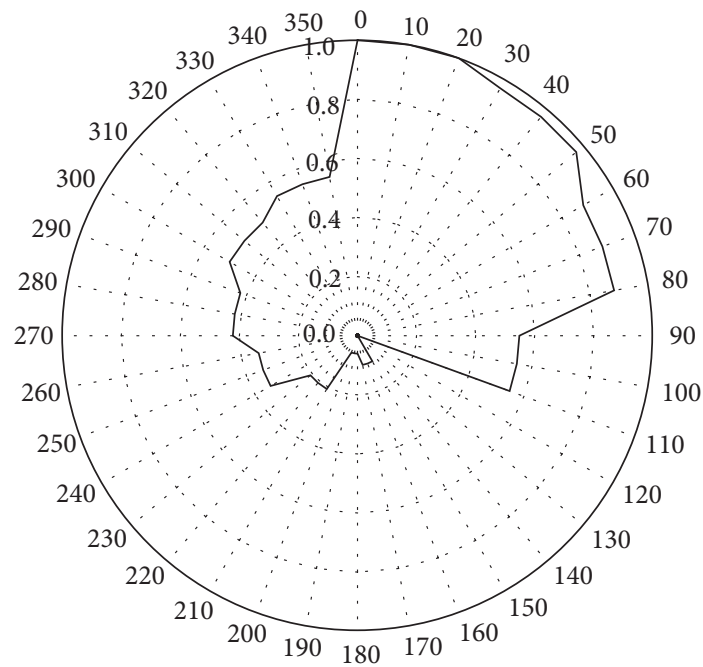

(c)

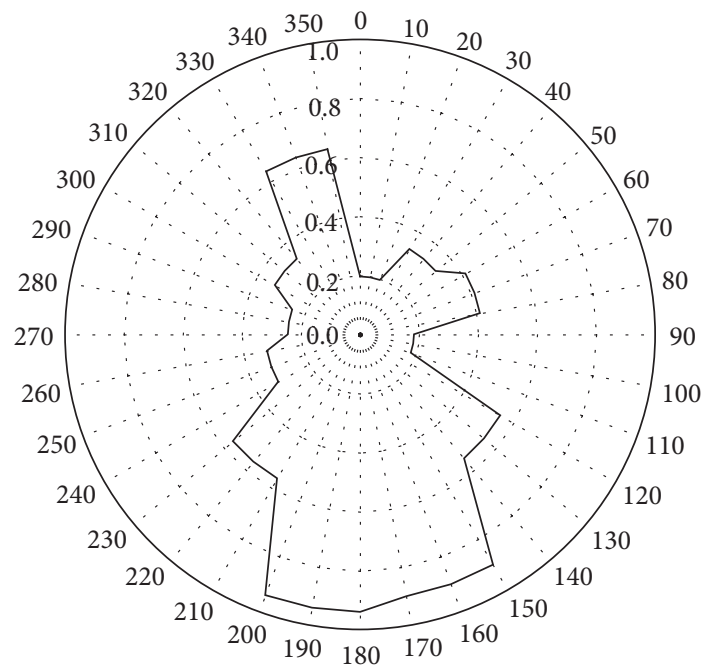

(e)

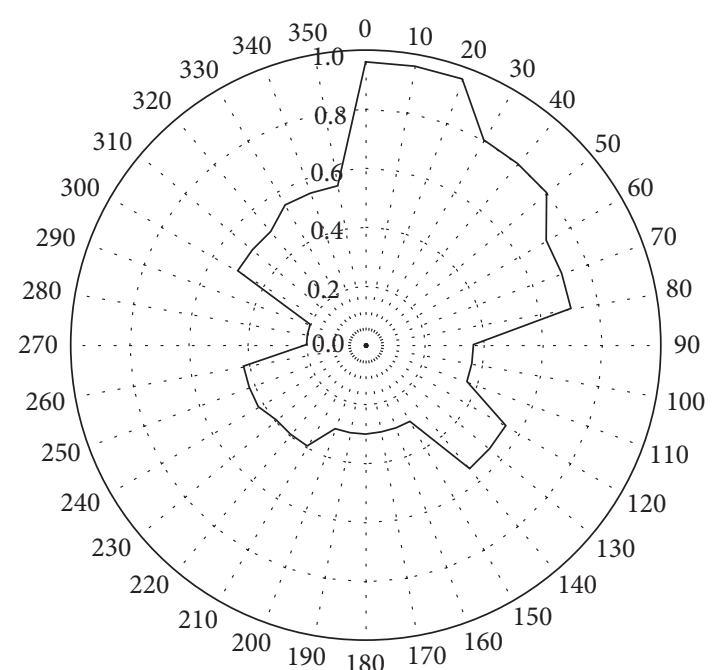

(b)

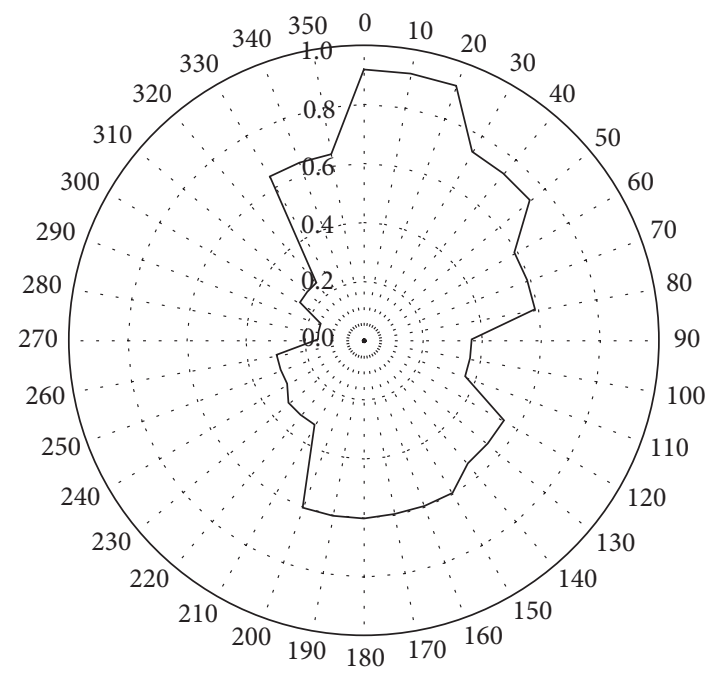

(d)

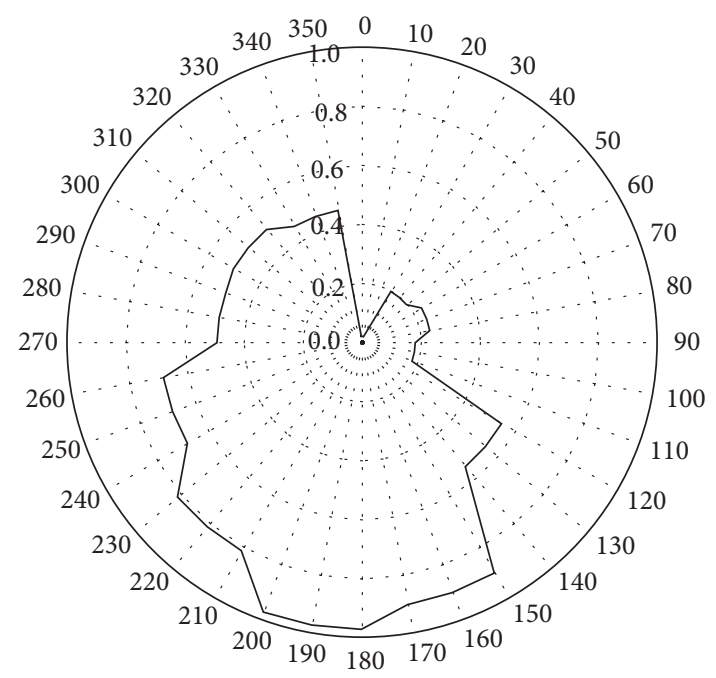

(f)

Figure 7: Rose plot of CPF for (a) the sum of PAHs, (b) the sum of hopanes, (c) the sum of $n$-alkanes, (d) the sum of 4-NO2-Phen and 2-OH-BA, (e) the sum of 3-OH-BA, 4-OH-BA, and 4-Me-PhA, and (f) the sum of $o$-PhA, $m$-PhA, $p$-PhA, 1,2,3-BA, 1,2,4-BA, and 1,2,4,5-BA at Hamilton. 
the PAH concentrations, possibly indicating traffic emissions in downtown Hamilton. The CPF plots for the oxygenated aromatic compounds showed that the sum of $4-\mathrm{NO}_{2}$-Phen and $2-\mathrm{OH}-\mathrm{BA}$ and the sum of $3-\mathrm{OH}-\mathrm{BA}, 4-\mathrm{OH}-\mathrm{BA}$, and 4-Me-PhA had also the similar wind sector dependence to the primary emission markers. However, the sum of $o$ $\mathrm{PhA}, m$-PhA, $p$-PhA, 1,2,3-BA, 1,2,4-BA, and 1,2,4,5-BA was dependent on southerly wind, indicating that their origins are different.

The CPF analysis for the Simcoe data (Figures 8(a)-8(f)) showed that the concentrations of PAHs, hopanes, $n$-alkanes, 4- $\mathrm{NO}_{2}$-Phen, and 2-OH-BA were high as the wind sectors were from $330^{\circ}-20^{\circ}$ (i.e., northerly wind) and $120^{\circ}-170^{\circ}$ (i.e., southeasterly wind). We could not identify this emission source located in the north of the sampling site at Simcoe. Chan and Mozurkewich [48] also found in this study that fine PM was likely transported from Toronto to the Simcoe sampling site; therefore, this long-range transport may be the explanation. The high concentrations from the southeasterly direction are explained by the influence from the coal-fired power plant. The CPF plots for the sum of 3-OH-BA, 4-OH-BA, and 4-Me-PhA and the sum of $o$-PhA, $m$-PhA, $p$-PhA, 1,2,3-BA, 1,2,4-BA, and 1,2,4,5-BA (polycarboxylic acids) showed different dependency, but both did not exhibit the similar trend to the primary emission markers, such as PAHs and hopanes. Their sources are likely different from the primary emissions. It is interesting to see that the group of 3-OH-BA, 4-OH-BA, and 4-Me$\mathrm{PhA}$ and the group of polycarboxylic acids showed similar dependency for the polycarboxylic acids observed at Hamilton. This is consistent with our previous conclusion that $o$-PhA, $m$-PhA, $p$-PhA, 1,2,3-BA, 1,2,4-BA, and 1,2,4,5-BA observed were contained in the air mass covering southern Ontario.

4.6. APCA. Scree plots of our APCA for up to ten loadings (or components) indicated more stable eigenvalues at Hamilton and Simcoe as more than three components were retained (Figures S-4a and 4b). It was found that the analysis with more than 3 loadings seemed to unnecessarily deconvolute the molecular marker signatures. To determine plausible number of loadings, we considered the following findings previously discussed. (1) From the analysis of PAH and hopane markers, vehicular emissions and coal (or similar petroleum fuel) combustion were more likely the major emissions sources at both sites. (2) At both sites, $4-\mathrm{NO}_{2}$-Phen and 2-OH-BA were originated from different emission source(s) compared to the other oxygenated aromatic compounds. (3) The emission source for 3-OH-BA, 4-OH-BA, and 4-Me$\mathrm{PhA}$ at Hamilton was different from their source at Simcoe, which is more likely the Nanticoke power plant. (4) $o$-PhA, $m$-PhA, $p$-PhA, 1,2,3-BA, 1,2,4-BA, and 1,2,4,5-BA were in the same concentration level at both sites and those can be of the same origin, secondary POM in the southern Ontario air. With consideration of these findings, we concluded that three factorial solutions of APCA seem to be the most plausible at Hamilton (Figure 9) and Simcoe (Figure 10). According to the marker distribution shown in Figure 9(a), plots of grey, red, and blue are vehicular emissions, unknown, and secondary products at Hamilton, respectively. Meanwhile, plots of grey, red, and blue at Simcoe seem to be coal combustion, vehicular emissions, and secondary products, respectively (Figure 10(a)). The results also demonstrated the limitation of APCA that the analysis could not differentiate vehicular emission and coal combustion at both sites; therefore, it should be noted that the plot in grey at both sites likely includes both sources. There was another problem that the plot in red at Hamilton, which is accompanied with $n$ alkanes and some of the oxygenated aromatic compounds, could not be identified. Since the majority of $n$-alkanes at Hamilton were expected to be the origin of vehicular emissions, the APCA seems to unsuccessfully deconvlute the emission sources for PAHs, hopanes, and $n$-alkanes at Hamilton. Those problems may be attributed to the fact that the number of our data points was limited. APCA on large datasets with respect to observations for longer time period would probably improve the results. Nevertheless, the combination of the plots in grey and red at both sites likely represents anthropogenic emissions, while the plot in blue represents the secondary POM. Time series plots of their scores (Figure 9(b) for Hamilton and Figure 10(b) for Simcoe) show that primary man-made emissions are the major source of POM in the southern Ontario air during the study period. However, it is worthwhile to note that, similarly to the late of the study period at both sites, the burden of polycarboxylic acids sometime became large. Combination of oxygenated aromatic compounds with VOC studies may gain a deeper insight into the production of secondary POM in the southern Ontario air.

\section{Summary}

Molecular marker analysis here demonstrated that PAHs, hopanes, and $n$-alkanes give valuable information of primary sources, particularly for vehicular emissions and coal combustion, while oxygenated aromatic compounds can be primary and/or secondary products. The paper here also demonstrated that, with combination of wind sector analysis and principal component analysis, the molecular marker can give more convincing evidence for source identification.

\section{Nomenclature}

PM: Particulate matter

$\mathrm{PM}_{10}$ : Particulate matter smaller than $10 \mu \mathrm{m}$ in aerodynamic diameter

POM: Particulate organic matter

TC: Total carbon

CPI: Carbon preference index

APCA: Absolute principal component analysis

PAHs: Polycyclic aromatic hydrocarbons

BaP: Benzo[a]pyrene

Ind: Indeno[1,2,3-cd]pyrene

BgP: Benzo[ghi]perylene

Cor: Coronene

TrisHp: Trisnorhopane

NorHp: Norneohopane

abHp: $\quad \alpha, \beta$-Hopane 


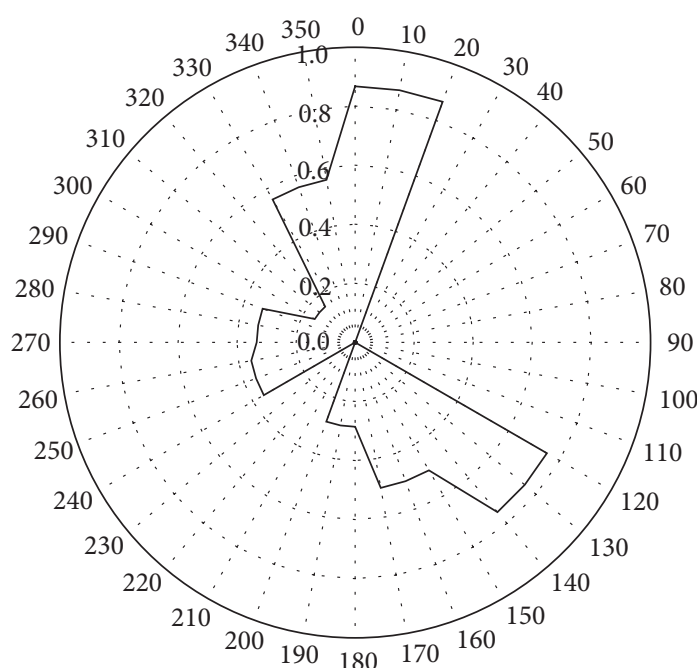

(a)

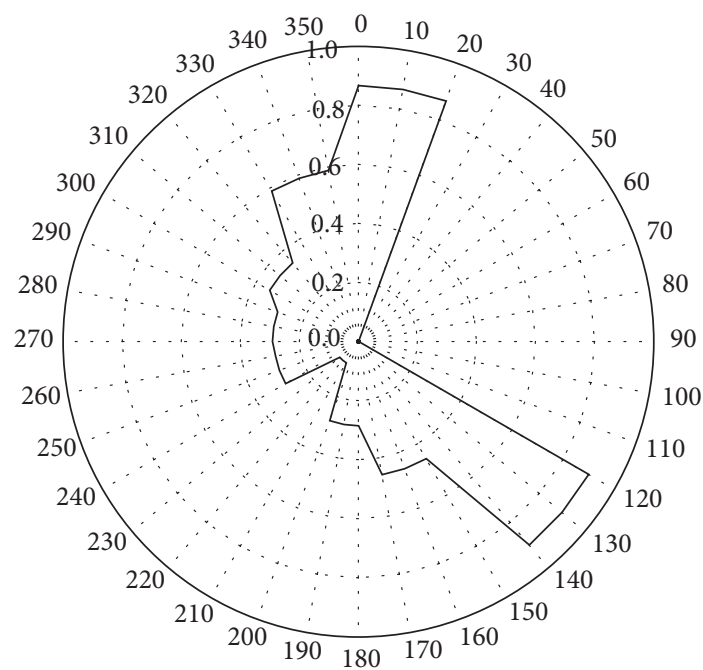

(c)

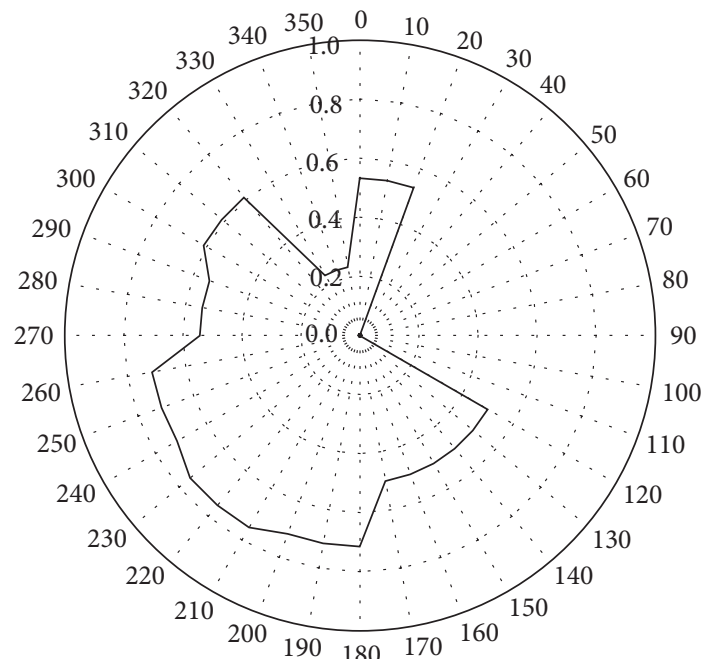

(e)

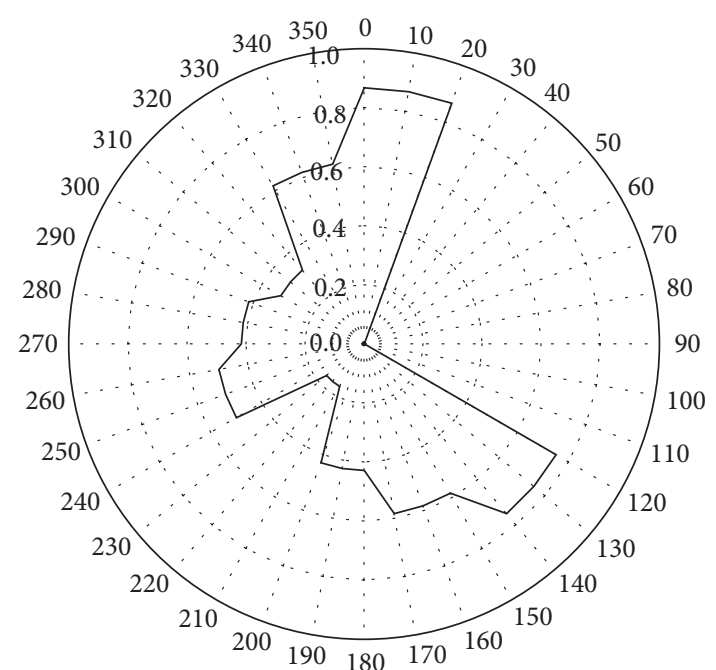

(b)

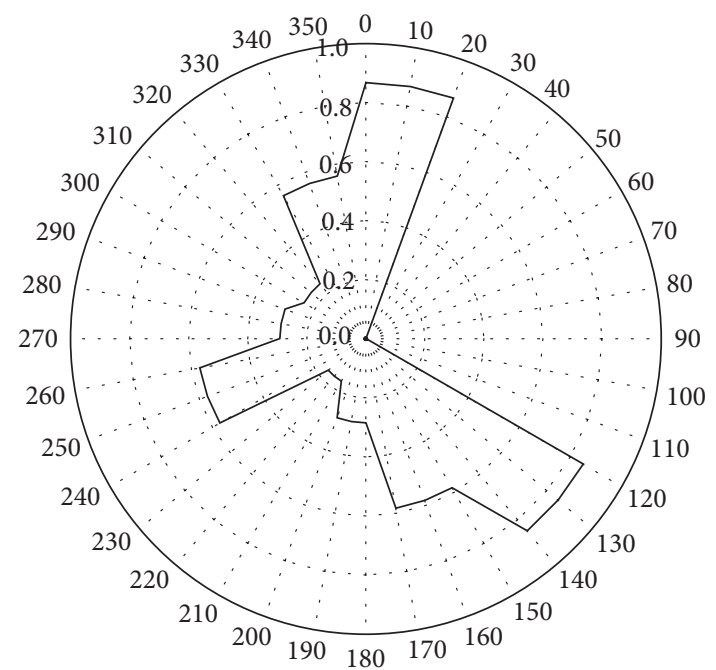

(d)

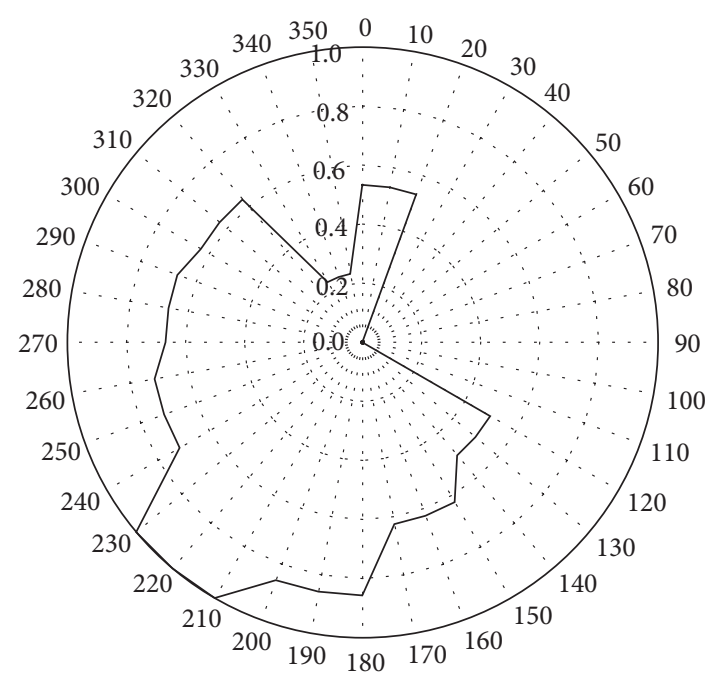

(f)

Figure 8: Rose plot of CPF for (a) the sum of PAHs, (b) the sum of hopanes, (c) the sum of $n$-alkanes, (d) the sum of 4-NO2-Phen and 2-OH-BA, (e) the sum of 3-OH-BA, 4-OH-BA, and 4-Me-PhA, and (f) the sum of $o$-PhA, $m$-PhA, $p$-PhA, 1,2,3-BA, 1,2,4-BA, and 1,2,4,5-BA at Simcoe. 


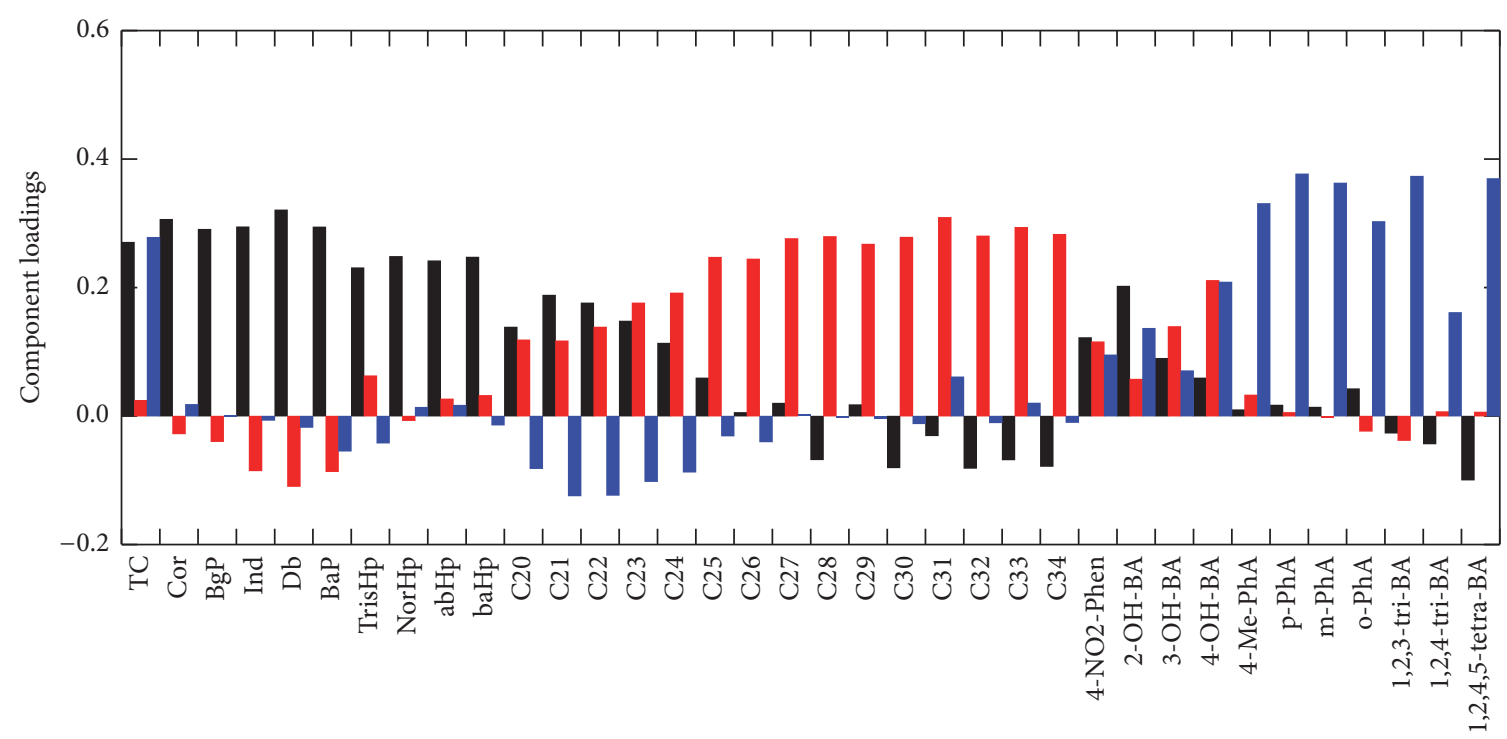

Species

Factor 1

Factor 2

- Factor 3

(a)

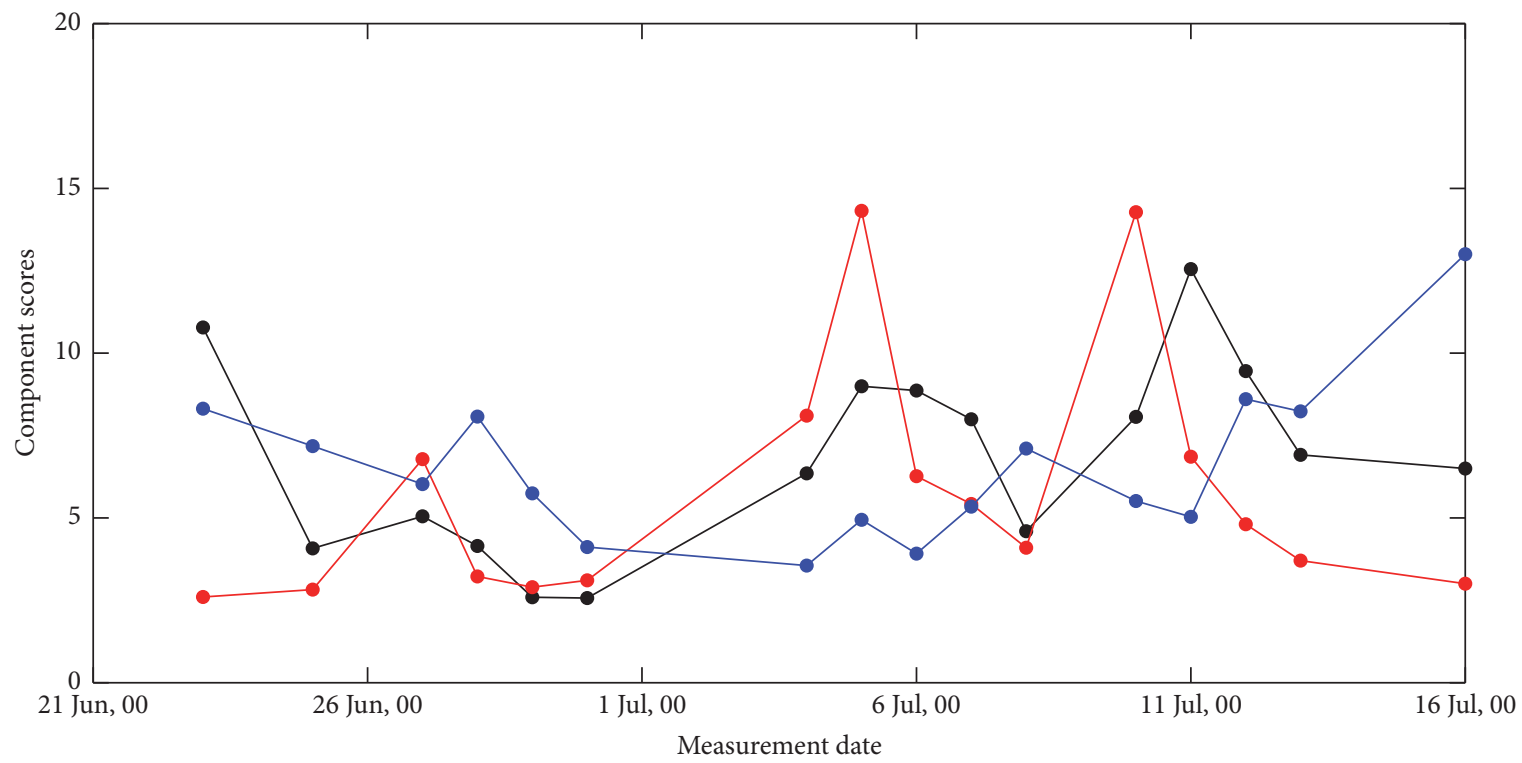

- Factor 1

- Factor 2

- Factor 3

(b)

FiguRE 9: (a) Loading of three factorial analyses and (b) time series score of three loadings for the Hamilton dataset.

baHp:

$\mathrm{C}_{20}$ to $\mathrm{C}_{34}$ :

$\beta, \alpha$-Hopane

$n$-Alkanes with the carbon numbers from

$\mathrm{C}_{20}$ to $\mathrm{C}_{34}$

4- $\mathrm{NO}_{2}$-Phen: 4-Nitrophenol

2-OH-BA: 2-Hydroxybenzoic acid

3-OH-BA: 3-Hydroxybenzoic acid

4-OH-BA: 4-Hydroxybenzoic acid
$o$-PhA: Ortho-phthalic acid

m-PhA: $\quad$ Meta-phthalic acid

p-PhA: $\quad$ Para-phthalic acid

4-Me-PhA: 4-Methylphthalic acid

1,2,3-BA: 1,2,3-Benzenetricarboxylic acid

1,2,4-BA: 1,2,4-Benzenetricarboxylic acid

1,2,4,5-BA: 1,2,4,5-Benzenetetracarboxylic acid. 


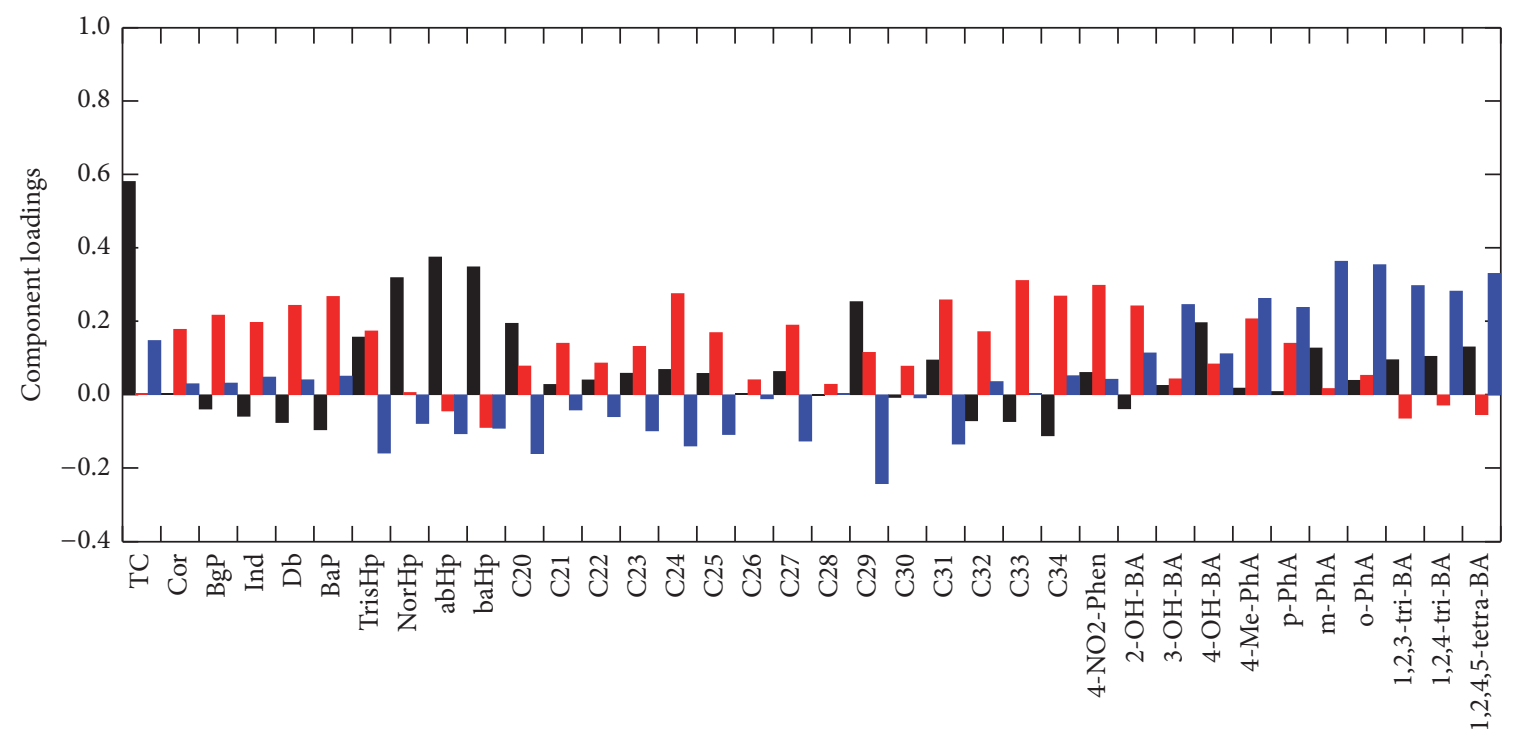

Species

Factor 1

Factor 2

Factor 3

(a)

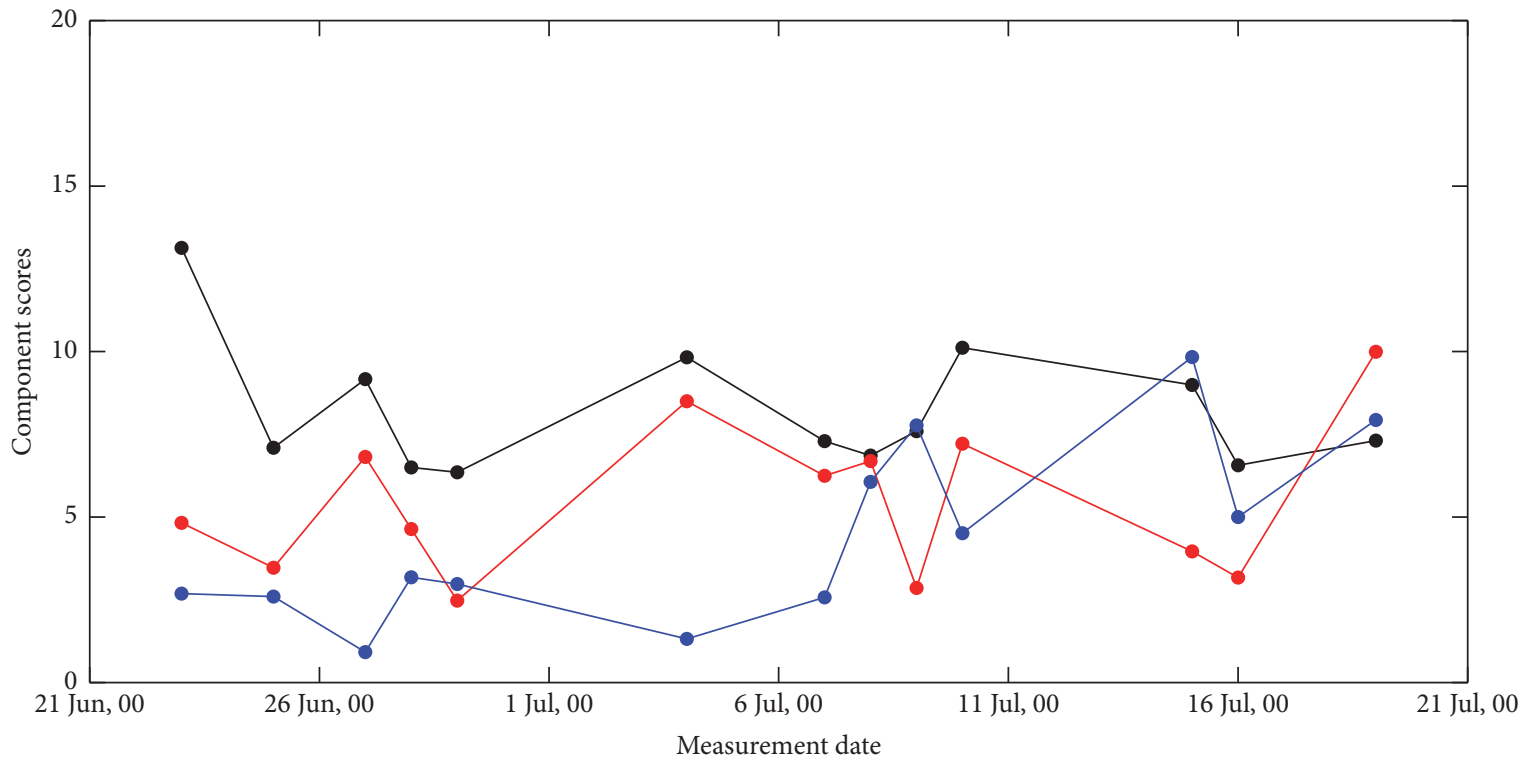

- Factor 1

- Factor 2

- Factor 3

(b)

FIGURE 10: (a) Loading of three factorial analyses and (b) time series score of three loadings for the Simcoe dataset.

\section{Disclosure}

Satoshi Irei is currently affiliated to the National Institute for Minamata Disease, 4058-18 Hama, Minamata, Kumamoto
867-0008, Japan. Jacek Stupak is currently affiliated to Institute for Biological Sciences, National Research Council of Canada, 100 Sussex Drive, Room 3121, Ottawa, ON, Canada K1A 0R6. 


\section{Conflicts of Interest}

The authors declare that there are no conflicts of interest regarding the publication of this paper.

\section{Acknowledgments}

The authors acknowledge Ontario Ministry of Environment for helping in the SONTAS 2000 studies. The authors also acknowledge TrizecHahn Technology for permitting the tunnel studies at the York Gateway Tunnel in downtown Toronto.

\section{References}

[1] S. Solomon et al., "Technical summary," in Climate Change 2007: The Physical Science Basis. Contribution of Working Group I to the Fourth Assessment Report of the Intergovernmental Panel on Climate Change, S. Solomon, D. Qin, M. Manning et al., Eds., Cambridge University Press, Cambridge, UK, 2007.

[2] World Health Organization Regional Office for Europe, Organization Regional Office for Europe, Health effects of particulate matter: Policy implications for countries in eastern Europe, Caucasus, and central Asia, 2013, http://www.euro.who .int/data/assets/pdffile/0006//Health-effects-of-particulatematter-final-Eng.pdf.

[3] J. L. Jimenez et al., "Evolution of organic aerosol in the atmosphere," Science, vol. 326, pp. 1525-1529, 2009.

[4] B. R. T. Simoneit, "Organic matter of the troposphere-III. Characterization and sources of petroleum and pyrogenic residues in aerosols over the western United States," Atmospheric Environment, vol. 18, no. 1, pp. 51-67, 1984.

[5] W. F. Rogge, L. M. Hildemann, M. A. Mazurek, G. R. Cass, and B. R. T. Simoneit, "Mathematical modeling of atmospheric fine particle-associated primary organic compound concentrations," Journal of Geophysical Research Atmospheres, vol. 101, no. 14, pp. 19379-19394, 1996.

[6] J. J. Schauer, W. F. Rogge, L. M. Hildemann, M. A. Mazurek, G. R. Cass, and B. R. T. Simoneit, "Source apportionment of airborne particulate matter using organic compounds as tracers," Atmospheric Environment, vol. 30, no. 22, pp. 38373855,1996 .

[7] M. Zheng, T. S. M. Wan, M. Fang, and F. Wang, "Characterization of the non-volatile organic compounds in the aerosols of Hong Kong - Identification, abundance and origin," Atmospheric Environment, vol. 31, no. 2, pp. 227-237, 1997.

[8] N. Yassaa, B. Youcef Meklati, A. Cecinato, and F. Marino, "Particulate n-alkanes, n-alkanoic acids and polycyclic aromatic hydrocarbons in the atmosphere of Algiers City Area," Atmospheric Environment, vol. 35, no. 10, pp. 1843-1851, 2001.

[9] A. E. Legzdins, B. E. Mc Carry, and D. W. Bryant, "Polycyclic Aromatic Compounds in Hamilton Air: Their Mutagenicity, Ambient Concentrations and Relationships with Atmospheric Pollutants," Polycyclic Aromatic Compounds, vol. 5, no. 1-4, pp. 157-165, 1995.

[10] T. Sihabut, J. Ray, A. Northcross, and S. R. McDow, "Sampling artifact estimates for alkanes, hopanes, and aliphatic carboxylic acids," Atmospheric Environment, vol. 39, no. 37, pp. 6945-6956, 2005.

[11] M. P. Fraser, Z. W. Yue, R. J. Tropp, S. D. Kohl, and J. C. Chow, "Molecular composition of organic fine particulate matter in
Houston, TX," Atmospheric Environment, vol. 36, no. 38, pp. 5751-5758, 2002.

[12] M. Zheng, G. R. Cass, J. J. Schauer, and E. S. Edgerton, "Source apportionment of PM2.5 in the southeastern United States using solvent-extractable organic compounds as tracers," Environmental Science and Technology, vol. 36, no. 11, pp. 23612371, 2002.

[13] M. P. Fraser, G. R. Cass, and B. R. T. Simoneit, "Gas-phase and particle-phase organic compounds emitted from motor vehicle traffic in a Los Angeles roadway tunnel," Environmental Science and Technology, vol. 32, no. 14, pp. 2051-2060, 1998.

[14] B. A. Benner Jr., G. E. Gordon, and S. A. Wise, "Mobile sources of atmospheric polycyclic aromatic hydrocarbons: A roadway tunnel study," Environmental Science and Techology, vol. 23, no. 10, pp. 1269-1278, 1989.

[15] D. J. Freeman and F. C. R. Cattell, "Woodburning as a source of atmospheric polycyclic aromatic hydrocarbons," Environmental Science \& Technology, vol. 24, no. 10, pp. 1581-1585, 1990.

[16] C. K. Li and R. M. Kamens, "The use of polycyclic aromatic hydrocarbons as source signatures in receptor modeling," Atmospheric Environment_Part A, vol. 27, pp. 523-532, 1993.

[17] T. Alsberg, U. Stenberg, R. Westerholm et al., "Chemical and biological characterization of organic material from gasoline exhaust particles," Environmental Science \& Technology, vol. 19, no. 1, pp. 43-50, 1985.

[18] W. F. Rogge, L. M. Hildemann, M. A. Mazurek, G. R. Cass, and B. R. T. Simoneit, "Sources of fine organic aerosol. 2. Noncatalyst and catalyst-equipped automobiles and heavy-duty diesel trucks," Environmental Science and Technology, vol. 27, pp. 636-651, 1993.

[19] D. R. Oros and B. R. T. Simoneit, "Identification and emission rates of molecular tracers in coal smoke particulate matter," Fuel, vol. 79, no. 5, pp. 515-536, 2000.

[20] M. J. Wornat, E. B. Ledesma, A. K. Sandrowitz et al., "Polycyclic aromatic hydrocarbons identified in soot extracts from domestic coal-burning stoves of Henan Province, China," Environmental Science and Technology, vol. 35, no. 10, pp. 1943-1952, 2001.

[21] S. Irei, "Direct Analysis of Low-Volatile Molecular Marker Extract from Airborne Particulate Matter Using Sensitivity Correction Method," International Journal of Analytical Chemistry, vol. 2016, Article ID 2834575, 2016.

[22] J. Rudolph and J. Stupak, "Determination of aromatic acids and nitrophenols in atmospheric aerosols by capillary electrophoresis," Journal of Chromatographic Science, vol. 40, no. 4, pp. 207213, 2002.

[23] X. Gong, Development and test of an on-line coupling of thermodesorption with fast gas chromatography for studies of nalkanes in atmospheric particulate matter [Ph.D. thesis], York University, Toronto, Canada, 2009.

[24] T. W. Chan and M. Mozurkewich, "Simplified representation of atmospheric aerosol size distributions using absolute principal component analysis," Atmospheric Chemistry and Physics, vol. 7, no. 3, pp. 875-886, 2007.

[25] M. P. Fraser, G. R. Cass, and B. R. T. Simoneit, "Particulate organic compounds emitted from motor vehicle exhaust and in the urban atmosphere," Atmospheric Environment, vol. 33, no. 17, pp. 2715-2724, 1999.

[26] B. R. T. Simoneit, "Organic chemistry of marine sediments," in Chem. Oceanograph, vol. 7, chapter 39, pp. 233-311, A Subsidiary of Harcourt Brace Jovanovich, 1978. 
[27] R. Eichmann, P. Neuling, G. Ketseridis, J. Hahn, R. Jaenicke, and C. Junge, "n-Alkane studies in the troposphere-I. Gas and particulate concentrations in north Atlantic air," Atmospheric Environment (1967), vol. 13, no. 5, pp. 587-599, 1979.

[28] B. R. T. Simoneit, "Organic matter of the troposphere - V: Application of molecular marker analysis to biogenic emissions into the troposphere for source reconciliations," Journal of Atmospheric Chemistry, vol. 8, no. 3, pp. 251-275, 1989.

[29] S. Kadowaki, "Characterization of carbonaceous aerosols in the Nagoya urban area. 2. Behavior and origin of particulate $n$ alkanes," Environmental Science \& Technology, vol. 28, no. 1, pp. 129-135, 1994.

[30] M. Zheng, M. Fang, F. Wang, and K. L. To, "Characterization of the solvent extractable organic compounds in PM2.5 aerosols in Hong Kong," Atmospheric Environment, vol. 34, no. 17, pp. 26912702, 2000

[31] B. R. T. Simoneit and M. Mazurek, "Organic matter of the troposphere - 2. Natural background of biogenic lipid matter in aerosols over the rural western United States," Atmospheric Environment, vol. 9, pp. 2139-2159, 1982.

[32] L. J. Standley and B. R. T. Simoneit, "Characterization of extractable plant wax, resin, and thermally matured components in smoke particles from prescribed burns," Environmental Science and Technology, vol. 21, no. 2, pp. 163-169, 1987.

[33] B. R. T. Simoneit, W. F. Rogge, Q. Lang, and R. Jaffé, "Molecular characterization of smoke from campfire burning of pine wood (pinus elliottii)," Chemosphere - Global Change Science, vol. 2, no. 1, pp. 107-122, 2000.

[34] D. R. Oros and B. R. T. Simoneit, "Identification and emission factors of molecular tracers in organic aerosols from biomass burning Part 1. Temperate climate conifers," Applied Geochemistry, vol. 16, no. 13, pp. 1513-1544, 2001.

[35] L. van Vaeck and K. van Cauwenberghe, "Cascade impactor measurements of the size distribution of the major classes of organic pollutants in atmospheric particulate matter," Atmospheric Environment (1967), vol. 12, no. 11, pp. 2229-2239, 1978.

[36] R. M. Kamens, J. N. Fulcher, and G. Zhishi, "Effects of temperature on wood soot pah decay in atmospheres with sunlight and low NOx," Atmospheric Environment (1967), vol. 20, no. 8, pp. 1579-1587, 1986.

[37] R. M. Kamens, Z. Guo, J. N. Fulcher, and D. A. Bell, "Influence of humidity, sunlight, and temperature on the daytime decay of polyaromatic hydrocarbons on atmospheric soot particles," Environmental Science and Technology, vol. 22, pp. 103-108, 1988.

[38] R. M. Kamens, J. Guo, Z. Guo, and S. R. McDow, "Polynuclear aromatic hydrocarbon degradation by heterogeneous reactions with $\mathrm{N} 2 \mathrm{O} 5$ on atmospheric particles," Atmospheric Environment Part A, General Topics, vol. 24, no. 5, pp. 1161-1173, 1990.

[39] S. R. McDow, "Effect of composition and state of organic components on polycyclic aromatic hydrocarbon decay in atmospheric aerosols," Environmental Science \& Technology, vol. 28, no. 12, pp. 2147-2153, 1994.

[40] S. H. Cadle, P. A. Mulawa, E. C. Hunsanger et al., "Composition of light-duty motor vehicle exhaust particulate matter in the Denver, Colorado area," Environmental Science and Technology, vol. 33, no. 14, pp. 2328-2339, 1999.

[41] "Ontario Ministry of Environment," Coal-Fired Electricity Generation in Ontario, 2001.

[42] J. K. Schneider, R. B. Gagosian, J. K. Cochran, and T. W. Trull, "Particle size distributions of $\mathrm{n}$-alkanes and $210 \mathrm{~Pb}$ in aerosols off the coast of Peru," Nature, vol. 304, no. 5925, pp. 429-432, 1983.

[43] M. A. Sicre, J. C. Marty, A. Saliot, X. Aparicio, J. Grimalt, and J. Albaiges, "Aliphatic and aromatic hydrocarbons in different sized aerosols over the Mediterranean Sea: Occurrence and origin," Atmospheric Environment (1967), vol. 21, no. 10, pp. 2247-2259, 1987.

[44] Y. Iinuma, O. Böge, and H. Herrmann, "Methyl-nitrocatechols: Atmospheric tracer compounds for biomass burning secondary organic aerosols," Environmental Science and Technology, vol. 44, no. 22, pp. 8453-8459, 2010.

[45] S. Inomata, A. Fushimi, K. Sato, Y. Fujitani, and H. Yamada, "4Nitrophenol, 1-nitropyrene, and 9-nitroanthracene emissions in exhaust particles from diesel vehicles with different exhaust gas treatments," Atmospheric Environment, vol. 110, pp. 93-102, 2015.

[46] H. Satsumabayashi, H. Kurita, Y. Yokouchi, and H. Ueda, "Photochemical formation of particulate dicarboxylic acids under long-range transport in central Japan," Atmospheric Environment Part A, General Topics, vol. 24, no. 6, pp. 14431450, 1990.

[47] M. Saccon, A. Kornilova, L. Huang, S. Moukhtar, and J. Rudolph, "Stable carbon isotope ratios of ambient secondary organic aerosols in Toronto," Atmospheric Chemistry and Physics, vol. 15, no. 18, pp. 10825-10838, 2015.

[48] T. W. Chan and M. Mozurkewich, "Application of absolute principal component analysis to size distribution data: identification of particle origins," Atmospheric Chemistry and Physics, vol. 7, no. 3, pp. 887-897, 2007.

[49] L. L. Ashbaugh, W. C. Malm, and W. Z. Sadeh, "A residence time probability analysis of sulfur concentrations at Grand Canyon National Park," Atmospheric Environment, vol. 19, no. 8, pp. 1263-1270, 1985.

[50] E. Kim and P. K. Hopke, "Comparison between conditional probability function and nonparametric regression for fine particle source directions," Atmospheric Environment, vol. 38, no. 28 , pp. 4667-4673, 2004. 

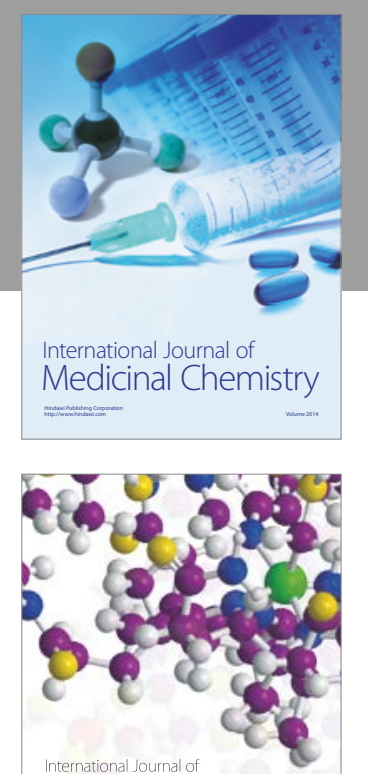

Carbohydrate Chemistry

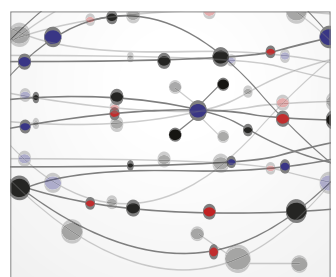

The Scientific World Journal
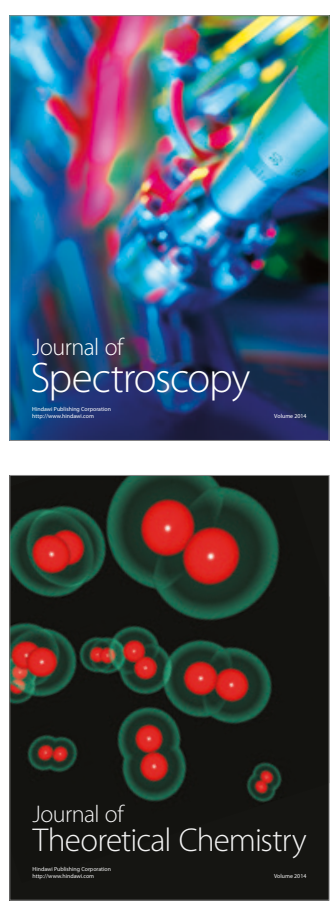
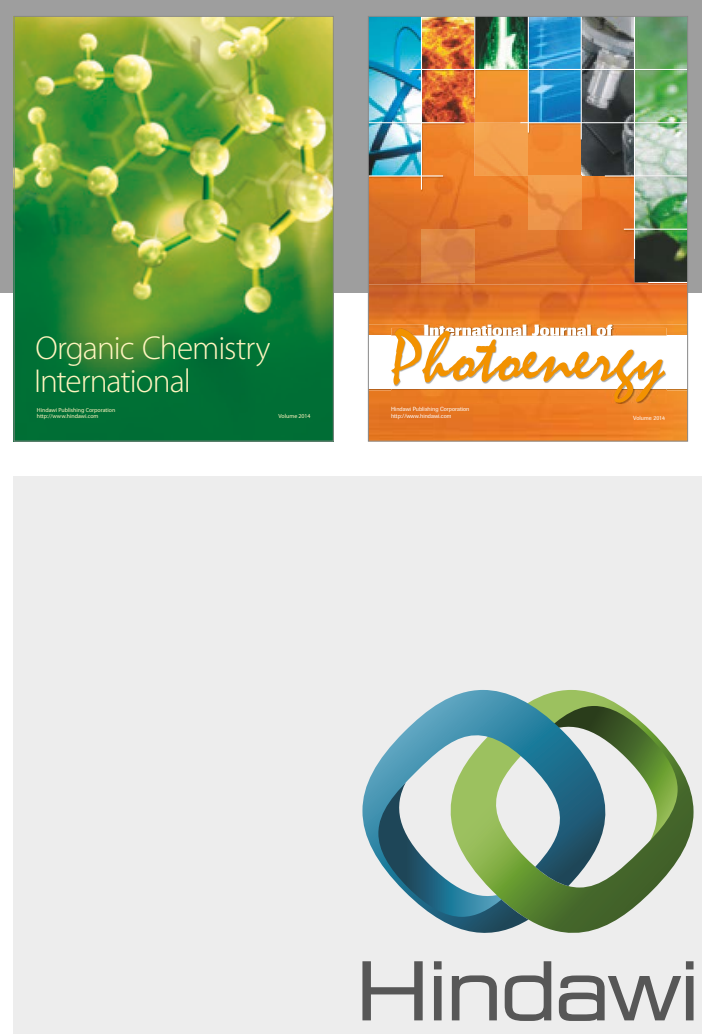

Submit your manuscripts at

https://www.hindawi.com

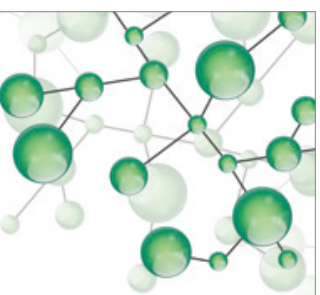

International Journal of

Inorganic Chemistry

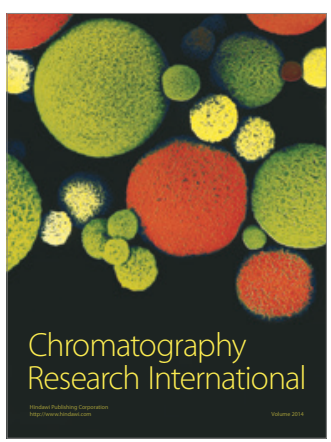

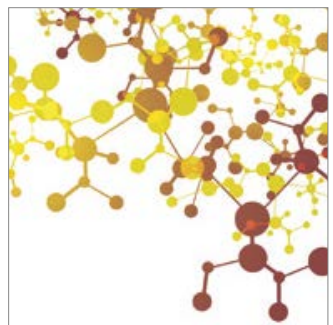

Applied Chemistry
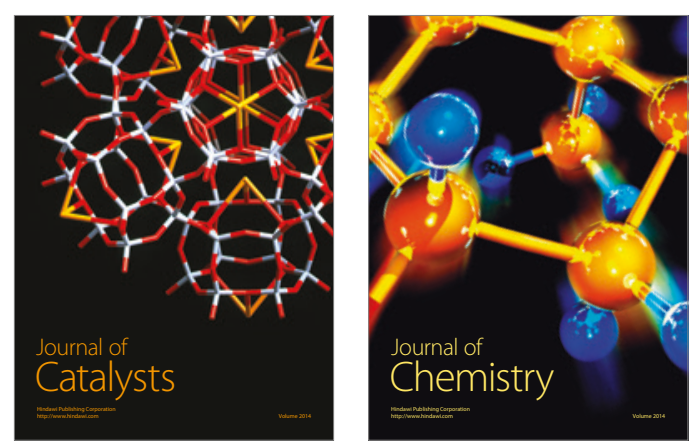
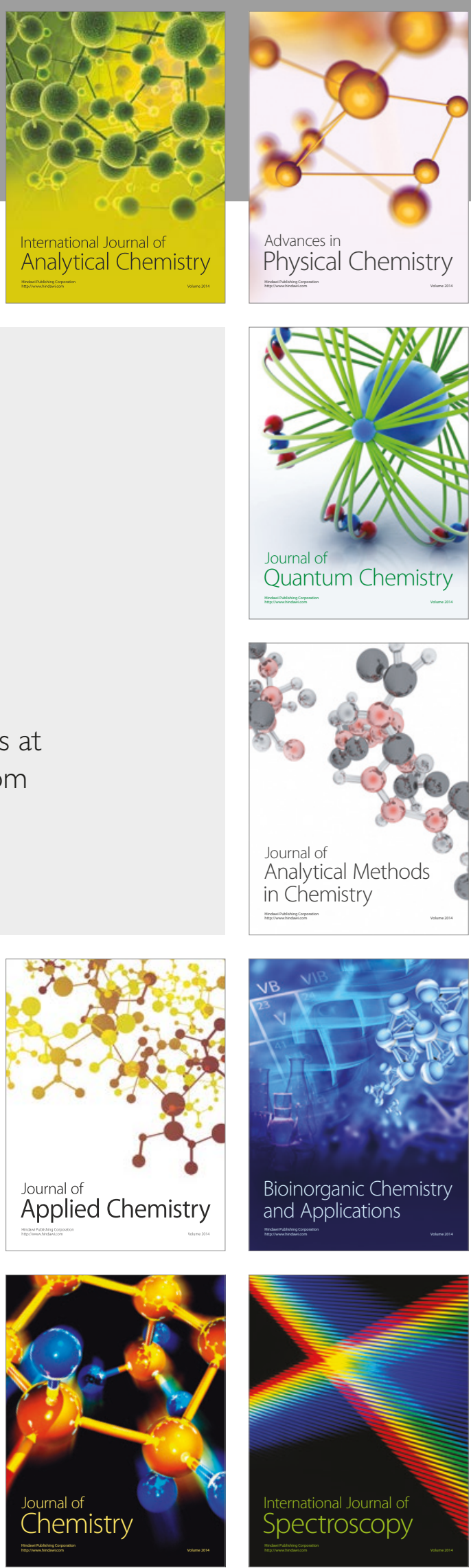